\title{
JOURNAL OF BIOENGINEERING AND TECHNOLOGY APPLIED TO HEALTH
}

An Official Publication of the Health Institute of Technology - ITS/SENAI CIMATEC

EDITOR-IN-CHIEF

Leone Peter Andrade

PUBLISHED BY SENAI CIMATEC

CIMATEC 奉 SIIEM:

March 2019

Printed in Brazil 


\section{JOURNAL OF BIOENGINEERING AND TECHNOLOGY APPLIED TO HEALTH}

An Official Publication of the Health Institute of Technology - ITS/SENAI CIMATEC

\section{EDITOR-IN-CHIEF}

Leone Peter Andrade

\section{DEPUTY EDITOR}

Roberto Badaró

\section{ASSISTANT DEPUTY EDITORS}

Alex Álisson Bandeira Santos (BR)

Lilian Lefol Nani Guarieiro (BR)

Valéria Loureiro (BR)

\section{ASSOCIATE EDITORS}

Alan Grodzinsky (US)

Bruna Aparecida Souza Machado (BR)

Carlos Coimbra (US)

Eduardo Mario Dias (BR)

Luiz Erlon Araújo Rodrigues (BR)

Frank Kirchner (DE)

Jorge Almeida Guimarães (BR)

Josiane Dantas Viana Barbosa (BR)

Milena Soares (BR)

Preston Mason (US)

Sanjay Singh (US)

Steven Reed (US)

Valter Estevão Beal (BR)
STATISTICAL ASSOCIATE EDITOR

Valter de Senna (BR)

\section{EDITORIAL BOARD}

Carlos Augusto Grabois Gadelha (BR)

Corey Casper (US)

Erick Giovani Sperandio Nascimento (BR)

George Tynan (US)

Hercules Pereira (BR)

Hermano Krebs (US)

Immanuel Lerner (IR)

Jailson Bittencourt de Andrade (BR)

James Chong (KR)

José Elias Matieli (BR)

Maria Lídia Rebello Pinho Dias (BR)

Mario de Seixas Rocha (BR)

Regina de Jesus Santos (BR)

Roberto de Pinho (BR)

Sanjay Mehta (US)

Vidal Augusto Zapparoli Castro Melo (BR)

Vilson Rosa de Almeida (BR)

\section{PRODUCTION STAFF}

Luciana Knop, Managing Editor

Valdir Barbosa, Submissions Manager

Flavia Carvalho, Secretary 


\section{JOURNAL OF BIOENGINEERING AND TECHNOLOGY APPLIED TO HEALTH}

Volume 2 ・ Number 1

March 2019

\section{Editorial}

Journal of Bioengineering and Technology Applied to Health: A New Journal of the Health Institute of Technology - ITS/SENAI CIMATEC

Leone Peter Andrade

\section{Original Papers}

Evaluation of PPC / mBio Inc.'s Biochip Reader Integrated Circuit Reader System for Diagnosis of HIV / HCV Infection: Preliminary Method .......3 Luciana Knop, Roberto Badaró, Chris Myat

\section{Review Articles}

Computational Fluid Dynamics Applied to Atherosclerosis Hemodynamics: A Brief Review. 15 Fernanda Sodré, Alex Álisson Bandeira Santos, Luzia A. Tofaneli, Turan D. Oliveira

\section{Health Innovation Innitiatives}

Study of Medical-Assistance Equipment, Orthotics, Prosthetics, and Special Materials in the Unified Health System (SUS) in Brazil .....21 Fotini Santos Toscas, Thiago Rodrigues Santos, Eduardo Jorge Valadares Oliveira

\section{Case Report}

Maintenance Management in a Health Care Establishment 27

Fabricio Avelino Bispo, Marinilda Lima Souza, Sérgio Pitombo

\section{Innovative Medical Products}

Mosquito Zero ${ }^{\mathrm{TM}}$

\section{Instructions for Authors}

\section{Statement of Editorial Policy}

\section{Checklist for Submitted Manuscripts}


The Journal of Bioengineering and Technology Applied to Health (JBTH) is an official publication of the Health Institute of Technology - ITS /SENAI CIMATEC. It is published quarterly (March - June - September - December) in English by SENAI CIMATEC Avenida Orlando Gomes, 1845, Piatã, Zip Code: 41650-010, Salvador-Bahia-Brazil; phone: (55 71) $3879-5501$. The editorial offices are at Health Institute of Technology at SENAI CIMATEC.

\section{Editorial Office}

Correspondence concerning subscriptions, advertisements, claims for missing issues, changes of address, and communications to the editors should be addressed to the Deputy Editor, Dr. Roberto Badaró, Journal of Bioengineering and Technology Applied to Health - JBTH - Avenida Orlando Gomes, 1845, Piatã, Zip code: 41650-010, Salvador-Bahia-Brazil; phone: (55 71) 3879-5501; or sent by e-mail: jbth@jbthonline.com.

\section{Permissions}

Journal of Bioengineering and Technology Applied to Health and Health Institute of Technology - ITS/SENAI CIMATEC. All rights reserved. Except as authorized in the accompanying statement, no part of the JBTH may be reproduced in any form or by any electronic or mechanic means, including information storage and retrieval systems, without

COVER: Imaging created by SENAY CIMATEC. All rights reserved. the publisher's written permission. Authorization to photocopy items for internal or personal use, or the internal or personal use by specific clients is granted by the Journal of Bioengineering and Technology Applied to Health and SENAI CIMATEC for libraries and other users. This authorization does not extend to other kinds of copying such as copying for general distribution, for advertising or promotional purposes, for creating new collective works, or for resale.

\section{Postmaster}

Send address changes to JBTH, Avenida Orlando Gomes, 1845, Piatã, Zip Code: 41650-010, Salvador-Bahia-Brazil.

\section{Information by JBTH-ITS/SENAI CIMATEC}

Home-page: www.jbthonline.com

E-mail: jbth@jbthonline.com

Phone: (55 71) 3879-5501 / 3462-9599.

\section{Copyright}

(C) 2019 by Journal of Bioengineering and Technology Applied to Health ITS/SENAI CIMATEC All rights reserved. 


\title{
Journal of Bioengineering and Technology Applied to Health: A New Journal of Health Institute of Technology - ITS/SENAI CIMATEC
}

\author{
Leone Peter Andrade* \\ Editor-in-Chief; Provost SENAI CIMATEC; Salvador, Bahia, Brazil
}

The Manufacturing and Technology Integrated Campi SENAI CIMATEC started the activities in March of 2002. CIMATEC is one of the most advanced campus for education, technology, and innovation of industry in Brazil. This is a private non-profit institution supported by the Federation Industry of Bahia that was created to upgrade the"National Technical Learning for Industries Support". Recently, CIMATEC became a university campus with 33 engineering and computer science technological areas. In the present time, SENAI is supported by a staff of over 650 members to support the activities of professional and higher education, and a Technology Center, all encompassed in the same building structure.

SENAI CIMATEC School of Engineering initiated operations in 2004, and currently offers nine Undergraduate degrees courses in Engineering, and a series of Graduate programs, including lato sensu (specializations and MBAs) and stricto sensu (Master's and Doctoral degrees). In 2008, the Industrial Management and Technology (GETEC) and the Computational Modeling and Industrial Technology (MCTI) Master's Programs were inaugurated. MCTI incorporated a Doctorate in 2010, and, GETEC also opened a Doctorate Program in 2016.

SENAI CIMATEC prides on delivering highly qualified professionals to the several industrial sectors, supporting innovation and problem-solution, having earned the recognition

Received on 10 October 2018; revised 16 October 2018.

Address for correspondence: Dr. Leone Peter Andrade. This editoria was used in the launch of the JBTH in October 2018 (Special Issue). Avenida Orlando Gomes, 1845, Piatã. Zip Code: 41.650-010, Salvador, Bahia, Brazil. Phone (5571) 3879-8401. E-mail: leone@fieb.org.br.

J Bioeng. Biotech. Appl. Health

2019;2(1):1-2.

(C) 2019 by SENAI CIMATEC. All rights reserved. of Brazilian Ministry of Education as the top Engineering School in the North/Northeast Regions of Brazil in the last five years, and one of the most important institutions in innovation and knowledge in the country.

Even though CIMATEC activities are carried on in a decade, it is already recognized as one of the main Science and Technology Institutions of the country. The National Confederation of Industry of Brazil (CNI) has acknowledged publicly that SENAI CIMATEC is a reference in the implementation of the network of SENAI Innovation Institutes (ISI) and SENAI Technology Institutes (IST). ISIs are strong allies of the Brazilian industry in the development of products, processes and applied research. In our campus, there are three ISIs and six ISTs installed since 2014: the ISIs in Automation, Metal Forming, and Material Unions and Logistics, and the ISTs in Civil Construction, Chemistry, Electrical and Electronics, Food Technologies, Electromechanical, Environment, and Health.

SENAI CIMATEC runs projects of high national and international impact to support companies from different regions of Brazil with a strong performance in Research, Development, and Innovation (R\&D\&I). Although, it maintains a network of partners that include prominent universities and organizations from all over the world in the field of Software and Supercomputing; Mobility and Infrastructure; Metrology and Development of New Products and Materials; Robotics and Automated Systems; Energy and Sustainability; Advanced Manufacturing; Micro and Small Enterprises (MSE), Biotechnology, and Health.

In this scenario, SENAI CIMATEC created the Health Institute of Technology (ITS) in 2017 under the leadership of a national and 
international recognized scientist medical, Roberto Badaro, MD, PhD., to organizes the interfaces of the existing engineering technology of CIMATEC, to support the health industrial and economic complex in the development of drugs, medicines, equipment, and materials that are strategic for the public health system of Brazil (Brazilian Unified Health System - SUS). For that purpose, the Institute is working on research, development, innovation, regulation, publications, education and management of economic and welfare data. The Health Institute of Technology will develop cutting-edge technology to meet the demands of research, development, and innovation (R\&D\&I) projects in the area of Healthcare, Chemical and Biotechnology and Devices Applied to Health, which includes:

\section{Chemical and Biotechnology based Industry}

- Test for quality control of Generic medications;

- Development of analytical techniques applied to the analysis of active substances in pharmaceutic, cosmetic and phytotherapeutic formulations;

- Development of monoclonal antibodies, as diagnostic or therapeutic agents;

Development of recombinant proteins;

Development of chemically synthesized drugs;

Development of adjuvants;

Development of new Active Pharmaceutical Inputs (IFAs).

\section{Equipment and Materials for Health Use}

- Development of electromedical equipment;

- Assistive technology development;

- New materials applied to implants;

- Integrated systems (software, microelectronics, and embedded electronics);

- Data management software (Big Data and Telemedicine);

- The E-Health;

- The augmented reality and virtual with medical applications (IoT);

- Robotic surgery;

- Development of diagnostic kits.
Quality, Regulation, and Management Incorporation of technologies in SUS; Economic regulation: the possibility of tax alteration; attracting foreign companies to Brazil from government incentives; certification and test of products;

- Management of economic data, epidemiological, regulatory, and development of new technologies (clinical trials).

The biotechnology and innovation market grows exponentially in Latin America. With the new purpose of incorporating 4.0 concept into the area of healthcare, an enormous number of new scientific information in technologies applied to health are available. A new journal devoted to publishing this information would help to foster collaborations in these technologies that can be applied to the development of health tools among scientists in the world.

In this sense, ITS/SENAI CIMATEC created The Journal of Bioengineering and Technology Applied to Health (JBTH) in order to open the opportunity to speed these collaborations. JBTH is a peer-review open access and multidisciplinary Journal with the aim to develop a platform for innovative researchers and scientists to explore the advanced and latest research developments in the field of Biomedical Engineering and related disciplines that are applied to the development of new tools for diagnostics and treatment in the area of healthcare.

JBTH will publish articles related to the most recent advancement discoveries and applications in the field of bioengineering, biotechnologies, Big Data, nanotechnologies, molecular engineering, biochips, medical electronics, medical devices and instrument guided surgeries, biomechanics, clinical engineering, genetic engineering, photonics, new therapeutic strategies including steam cell therapies, gene therapy, new molecular biology discoveries and any scientific reliable information on advanced and very latest research topics. 


\title{
Evaluation of PPC / mBio Inc.'s Biochip Reader Integrated Circuit Reader System for Diagnosis of HIV / HCV Infection: Preliminary Method
}

\author{
Luciana Knop*1; Roberto Badaró1; Chris Myat ${ }^{2}$ \\ ${ }_{1}^{1}$ Health Institute of Technology - SENAI-CIMATEC; Salvador, BA, Brazil; \\ $2 \mathrm{~m} /$ Bio Diagnostics Inc. Precision Photonic Corporation, CO; USA
}

\begin{abstract}
The technological advances of recent decades in immunodiagnostic techniques have enabled the development of methods capable of detecting the antigen-antibody complex with high efficiency and reliability. However, the cost of such procedures has remained high; they are not easy to handle for an unskilled professional, nor provide immediate results for multiple samples. Precision Photonics Corporation (PPC), with $\mathrm{m} /$ Bio Inc. and in partnership with the University of San Diego (UCSD), USA, created an integrated circuit reader (Biochip Reader), which is low cost, fast and easy to handle, based on an optical systems and multiplex arrangements for the detection of biological multi-markers at the same time. This study aimed to evaluate the operation of the integrated circuit reader system (Biochip Reader), the protocols and the results of the multiplex tests for antibodies against HIV and HCV in partnership with the Federal University of Bahia (UFBA). We tested a total of 65 samples in the Biochip reader, and they showed $100 \%$ of sensitivity and specificity when compared to the results obtained by ELISA for HIV and HCV. Nevertheless, the protocols and the results obtained in Bahia presented slide instability, such as the formation of crystals and trehalose residues, unnecessary steps and manipulation of the slides. This fact led to changing the protocol and improving the prototype. However, more tests with new biomarkers are needed to validate the method.
\end{abstract}

Keywords: Biochip. Biosensor. HIV. HCV. Integrated circuit. Optical system. Fluorescence.

Infectious diseases have been one of the most significant public health problems in the world. Despite the diagnostic advances in medicine they still account for one in three deaths occurring worldwide [1]. In recent decades, technological progress has enabled the development of methods capable of detecting the antigen-antibody complex with high efficiency and reliability, through immunological techniques that reveal sensitivity to antigens (intradermal and percutaneous reactions), presence of antibodies or antigens in the body, (immunofluorescence, radioimmunoassay, enzymelinked immunosorbent assay, immunofluorimetry and chemiluminescence assays) [2]. Despite rapid tests, several immunodiagnostic tests still require specialized professionals to perform the

Received on 15 January 2019; revised 12 February 2019. Address for correspondence: Dr. Luciana Knop. Avenida Orlando Gomes, N. 1845, Piatã. Zip Code: 41650-010. Salvador, Bahia, Brazil. Phone: (+55 71) 3879-5501. E-mail: lbknop@hotmail.com.

J Bioeng. Biotech. Appl. Health 2019;2(1):3-14. C 2019 by SENAI CIMATEC. All rights reserved. procedures, an appropriate place for processing, specific materials and reagents and time for the determination of the results.

To create fast, cost-effective clinical diagnostic tests without the need for specialized professional, with little biological material, the Precision Photonics Corporation (PPC), in partnership with University of San Diego (UCSD), enhanced a biochip reader. This method was based in microarray-technology with an integrated circuit and photonic system for rapid and cost-effective diagnosis of numerous infectious diseases (PPC/ mBio Inc. - Biochip Reader). The Federal University of Bahia (UFBA), Brazil, joined this project to use this technique in the diagnosis of HIV, HCV, and related coinfections.

In this study, we present the results of Phase 2 of the project, with significant and promising results in the validation of biosensors for HIV and HCV. The Federal University of Bahia performed this Phase of the project in collaboration with Precision Photonics Corporation (PPC), mBio Diagnostic Inc., and the Division of Infectious Diseases of the University of San Diego (UCSD), California, 
USA, and the tests have been carried out in Brazil supported by Research Support Foundation of the State of Bahia (FAPESB).

\section{Development of Biochip Readers/Biosensors (Biochip Reader)}

\section{Naval Research Laboratory (NRL)}

The Multi-Analyte Array Biosensor (MAAB) was developed by the Naval Research Laboratory (NRL) of Washington (DC), USA, to detect and identify multiple analytes simultaneously [3]. The Biochip Reader is an electronic instrument developed for the detection of nanograms of toxins, allergens, proteins, bacteria, parasites or antibodies and antigens, using a minimal amount of biological material, without the need for specific processes $[4,5]$.

The NRL biosensor was designed using the microarray system and to be used with a laptop for fluid control, data analysis and storage [6]. Due to their selectivity and sensitivity, immunoassays were the first choice for the development of rapid identification methods using the fluorescencebased RL array biosensor [3].

\section{Precision Photonics Corporation}

Precision Photonics Corporation (PPC), USA, proposed a research and development program aimed at low-cost technology for the diagnosis of HIV and related coinfections. Due to the global nature of the disease and diagnostic products on the market, it was necessary to qualify the development tool outside the United States to assess its performance in a population with different conditions. Therefore, PPC and the corporate division of mBio Diagnostic adapted the biosensor of NRL arrangements and successfully developed prototypes of a low-cost diagnostic tool for infectious diseases. A biochip (consumer disposable) - containing the analytic for recognition; the transducer (non-disposable); and the reader (non-disposable) are the basement of this equipment (Figure 1).
Figure 1. Biochip Reader Model.

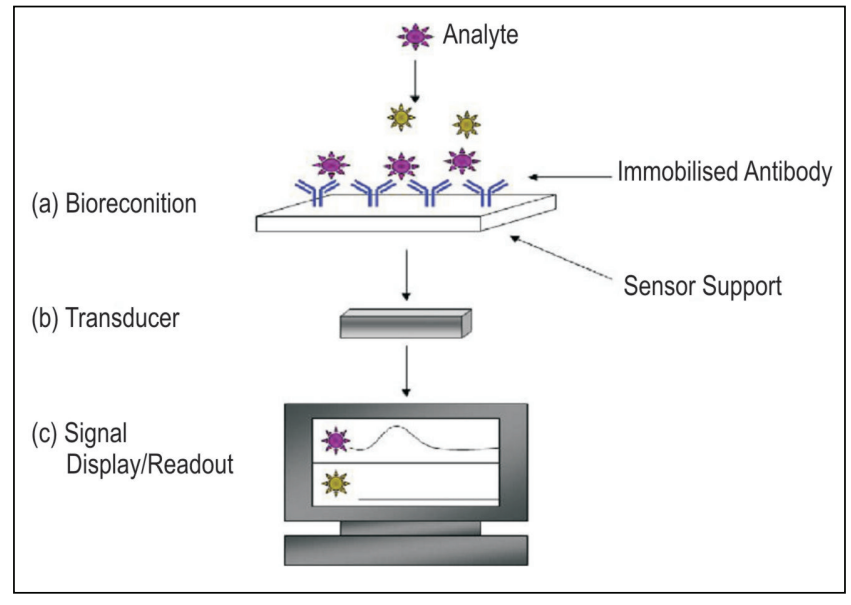

\section{Development of the Biosensor by PPC}

The biochip's PPC reader is a fluorescencebased laser optical detection system and uses a laser diode, and a CMOS or CCD toner comprised the source and the detector. The equipment consists of a laptop, a multi-pathogens biosensor (reader) to detect analytes at one time, a separate interface to avoid contamination (Figure 2a - details in Figure 3 ) and the 'slides' in the form of microarray strips, previously sensitized (Figure 2b). It is simple, portable, easy-to-operate equipment that requires minimal sample preparation and low-power handling, and it is appropriate for use in rural areas and districts with poor socioeconomic conditions.

\section{Methods of Biochips Units (Diagnostic Cards)}

The biochip (diagnostic card) is a miniaturized plastic strip, arranged in microarrays, with the presence of negative and positive controls and sensitized with the antigens of HIV and HCV. The preparation of these strips specifically for these target pathogens occurred in Phase 1 in the United States.

\section{Preparation of Biochips to Phase II}

The samples were placed in closed containers and pumped directly into the chips at Precision Photonics Corporation (PPC), USA. Thus, the chips (slide/trips) (Figure 2b) presented specific areas containing concentrations of antigens by enzymelinked immunoassays, such as the indirect ELISA 
Figure 2. (a) Biochip Reader; (b) slides (trips) in micro-arrays (biochip) previously previamente sensitized.

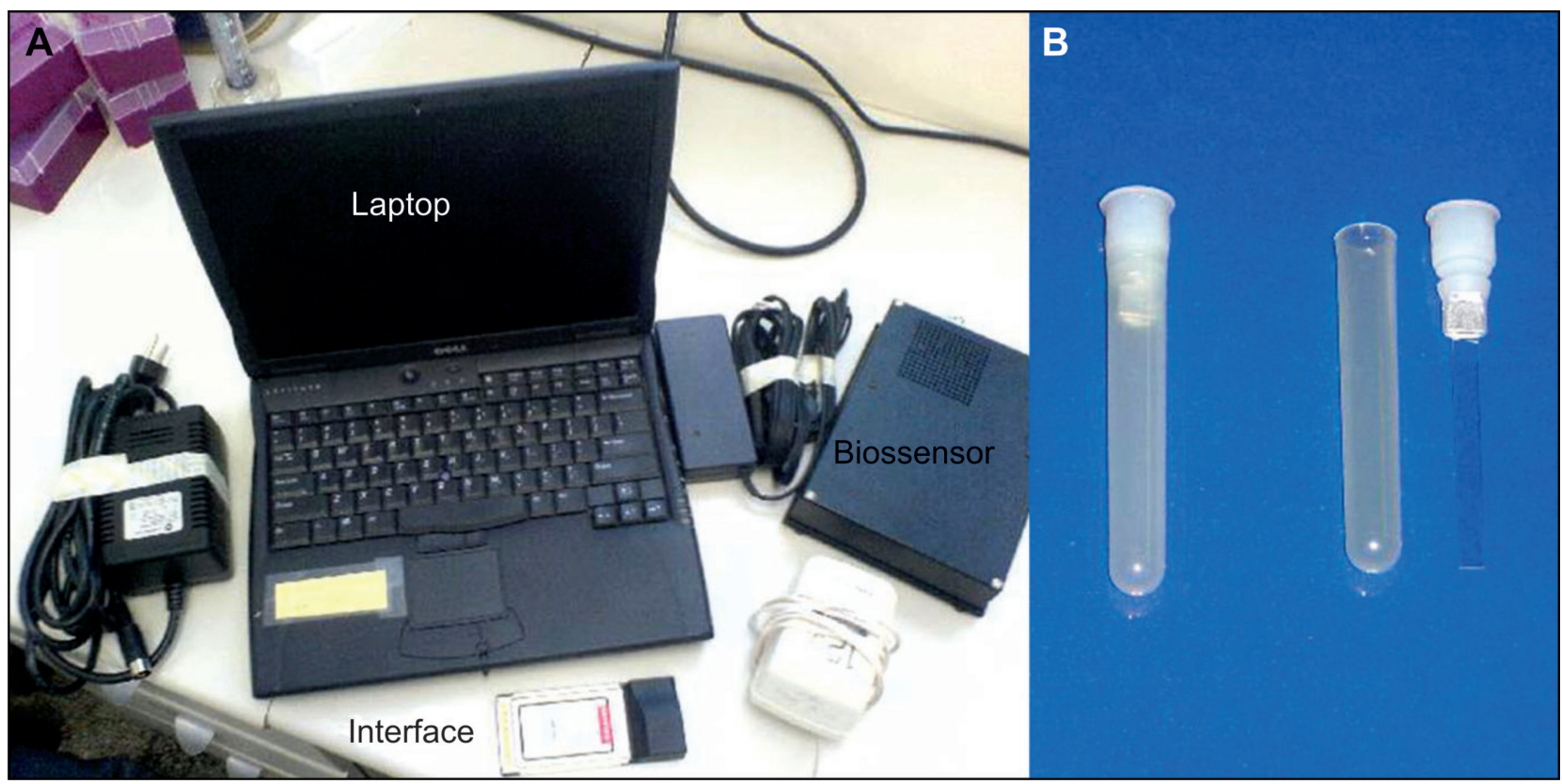

Figure 3. Biosensor detail.

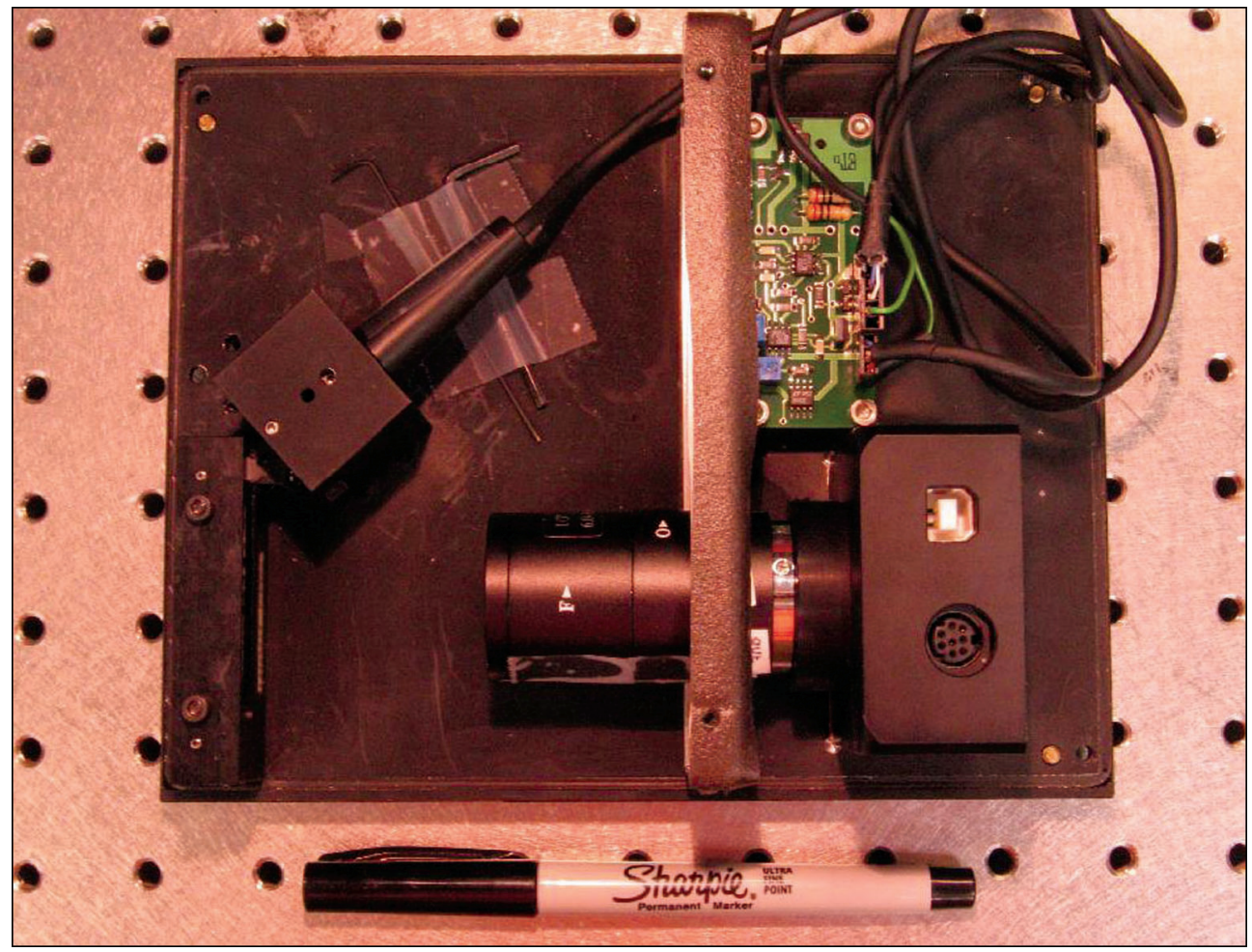


technique. Subsequently, each pathogen was identified electronically and placed within a particular location where the pumping of the sample was directed (Biodot-Arrayer). In this stage of construction, doseresponse curves were prepared for each pathogen to compare the results obtained in Phase I.

\section{The Study}

The Laboratory of Tropical Diseases of the University Complex Prof. Edgard Santos (HUPES) at the Federal University of Bahia (UFBA) conducted this study. It consisted of the evaluation and application of the material sent by PPC / mBio, which include: strips/slides already previously sensitized and blocked in the USA (Biochip Reader with BCRanalysis software and runcamera.exe installed on a laptop), protocols 1 and 2; using the samples (sera/plasma) collected and data provided from HUPES patients as well as materials and reagents.

We selected 65 sera/plasma from patients positive and negative for HIV, HCV, and HTLV and related coinfection. We chose randomly 52 old sera from the Tropical Diseases Laboratory, following protocol 1 (Figure 4); and 13 (7 sera and 6 plasma) during protocol 2 (Figure 5).

This project was approved by the National Committee for Research Ethics (CONEP) of UFBA on June 20, 2006, under number 60/2006 and is still in force. The classification of this article, according to the Classification System for Journal Articles of the Journal of Economic Literature (JEL), is I1.

\section{Protocol and Procedures Tests}

PPC/mBio (Figures 4 and 5) sent two protocols for the tests carried out in Bahia. Protocol 1 (Figure 4) showed antigens for the HCV core and HIV gp41 protein viral envelope. Protocol 2 (Figure 5), in addition to the antigens referred to in the previous protocol, the antigens of the HIV gp120 proteins, HCVNS3, and the reduction of a spots grid for both positive and negative control were inserted, and the protocol included a large number of spots for human IgG control. Besides, spots containing HIV gp41 antigen were enlarged.
Regarding the reagents and procedures adopted, the two protocols were identical.

The protocols provided the procedures: (1) strip washing and new blocking; (2) incubation with the human serum samples; (3) incubation with labeled antibody; (4) rinsing, drying and image detection on the reader (Biochip Reader).

We obtained human serum samples with HIV / HCV (+/-), (-/+) and (-/-) from the serum bank of the Tropical Medicine Laboratory at the Federal University of Bahia. The blocking buffer used was commercial Pierce buffer, mixed in the ratio of $1: 1$ with the Tris-EDTA buffer. Detection of the labeled antibody used was anti-human IgG Alexa 647 (Invitrogen / Molecular Probes).

Data Analysis and Determination of Exposure Time

BCRanalysis performed the Data analysis by the software of the Biochip Reader, which analyzed the image-points with specific programming. This programme probes the intensities of the spots for HIV and $\mathrm{HCV}$ were relative to the positive and negative controls in the same slide. PPC/mBio defined the cut-off in the procedures forwarded to designate the positive or negative result, using the pre-programming of $<255 \mathrm{~ms}$, without the use of background subtraction and images with 1280x1024 pixels.

\section{$\underline{\text { HIV/HCV Sensitized Slides }}$}

Patients' sera were identified according to positivity or negativity alone or with coinfection, as described in Table 1.

Table 1. Tested samples of HIV, HCV, HTLV negative and positive patients and coinfection related.

\begin{tabular}{lccccc}
\hline Slides & \multicolumn{5}{c}{ Patients (N=65) } \\
\cline { 2 - 6 } /Infection & HIV+ & HIV- & HCV+ & HCV- & Total \\
\hline HIV* & 25 & 0 & 0 & 25 & 25 \\
HCV* $^{*}$ & 0 & 13 & 13 & 0 & 13 \\
HTLV* & 0 & 6 & 0 & 6 & 6 \\
HIV+HCV & 9 & 0 & 9 & 0 & 9 \\
HIV+HTLV & 6 & 0 & 0 & 6 & 6 \\
HCV+HTLV & 0 & 6 & 6 & 0 & 6 \\
Subtotal & $40 * *$ & $25 * *$ & $25 * *$ & $37 * *$ & $65 * * *$ \\
* Monoinfected patients. ** Total of patients with or without \\
infection. *** Overall of patients.
\end{tabular}


Figure 4. PPC/mBio Protocol 1. Disposition of HIV gp41 protein viral envelope, HCV core antigens, and positive and negative controls on the slides.

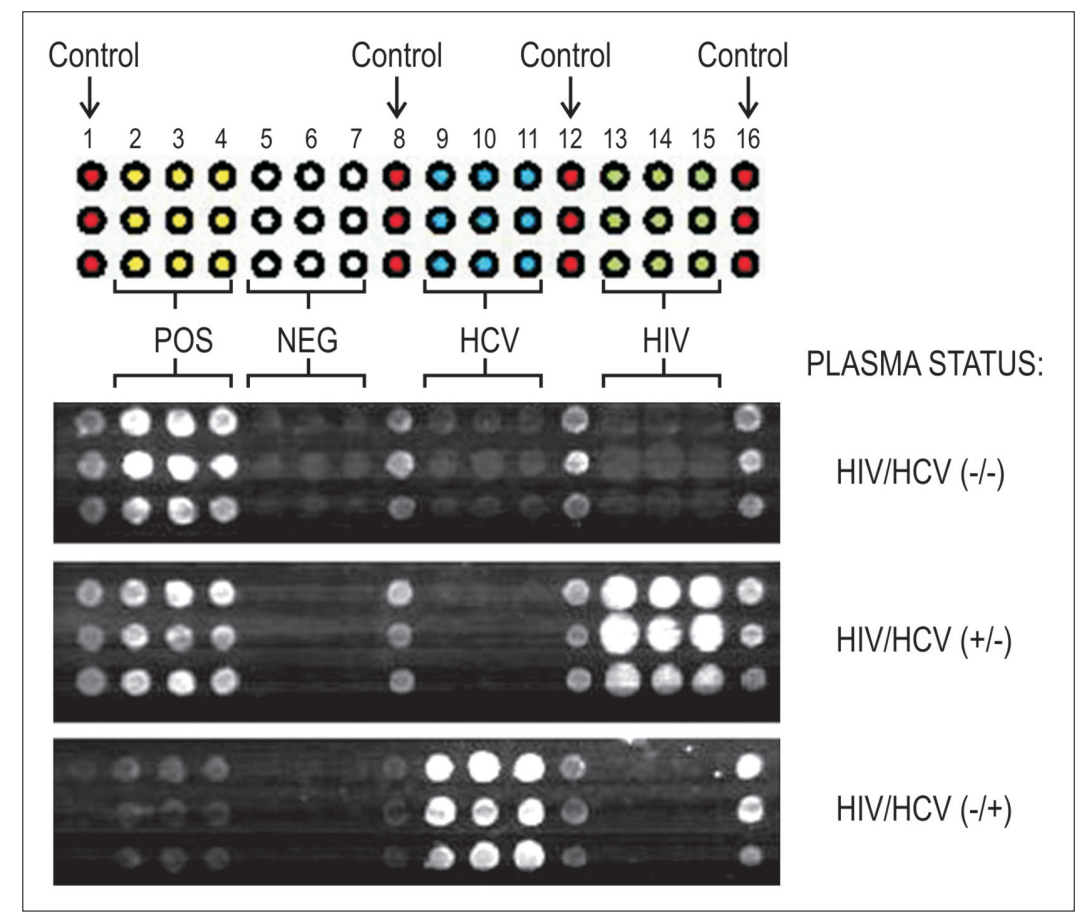

Figure 5. PPC/mBio Protocol 2. Disposition of gp41 and gp120 HIV antigens, core and Nns3HCV antigens, and positive and negative controls on the slides.

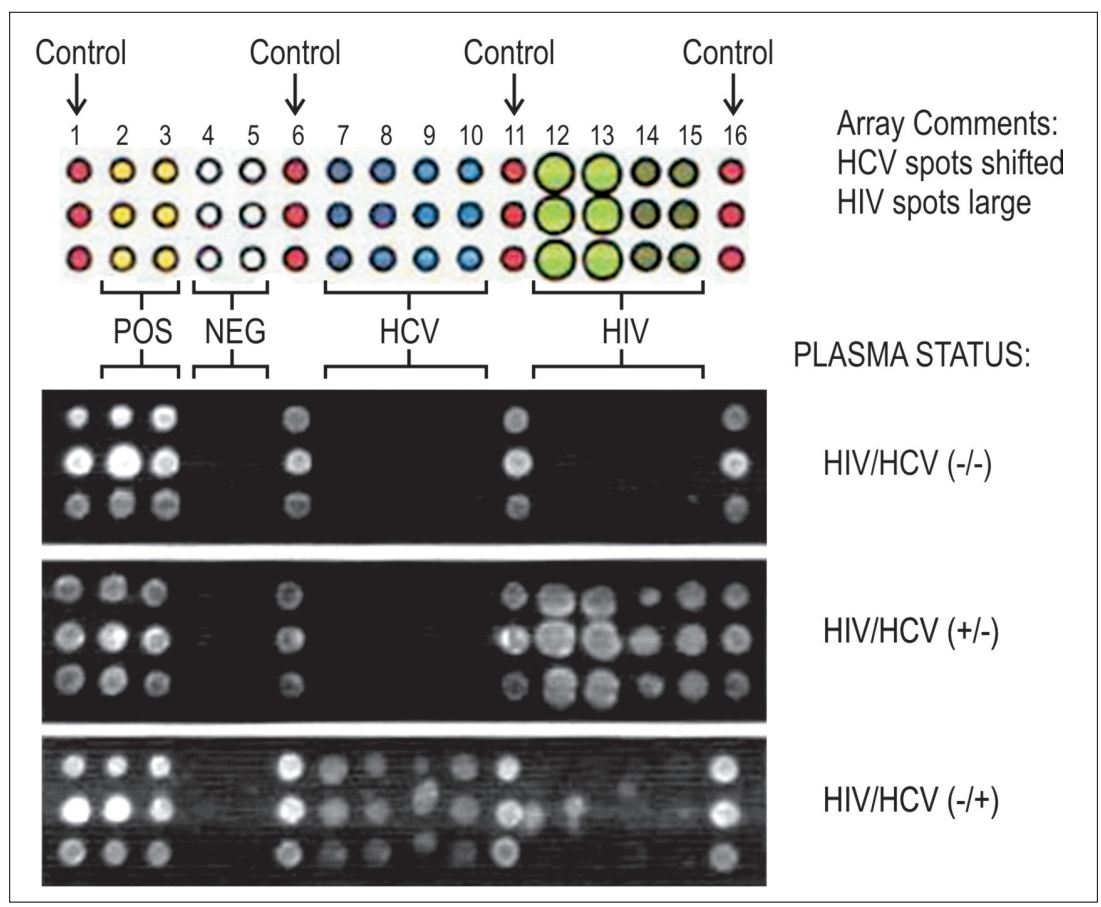


Figure 6. HIV/HTLV positive patient. Slide shows HIV positive patient.

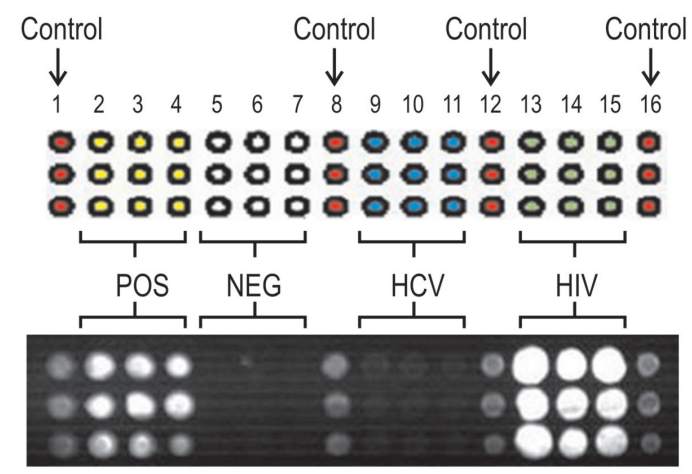

Figure 7. HIV/HCV/HTLV negative patient. Slide shows HIV/HCV negative patient.

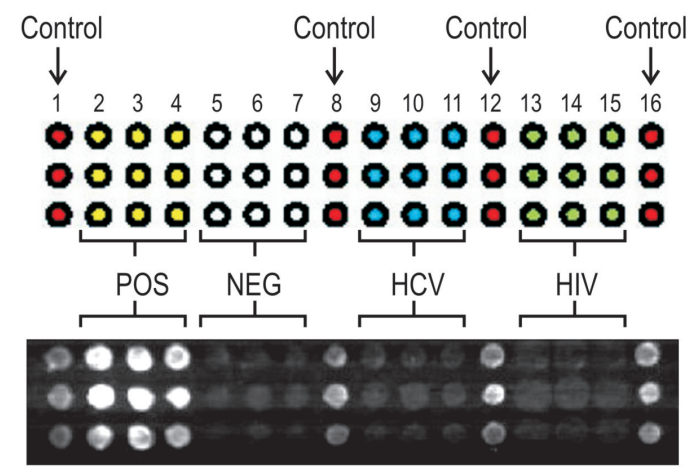

Figure 8. HIV/HCV positive and HTLV negative patient. Slide shows HIV/HCV positive patient.
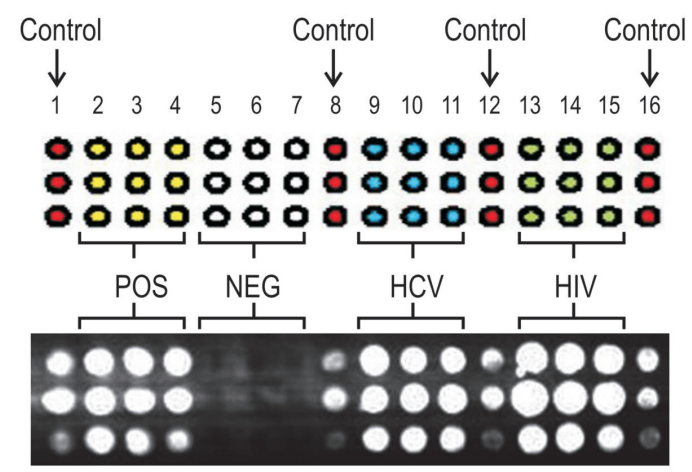

Figure 9. HIV/HCV/HTLV positive patient. Slide show HIV/HCV positive patient.

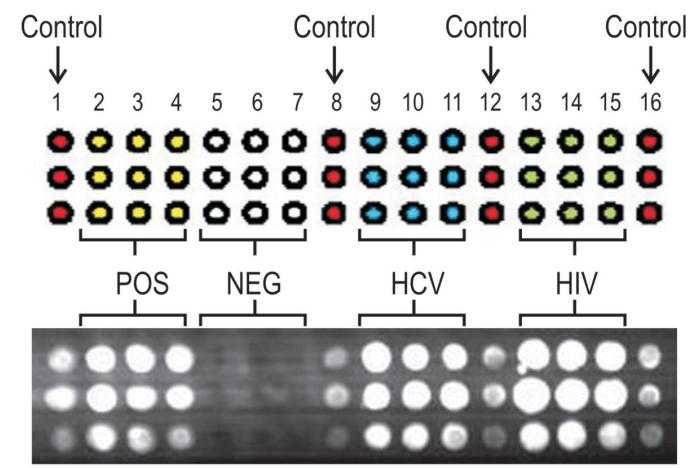


Figure 10. HCV/HTLV positive patient. Slide shows HIV negative and HCV positive patient.

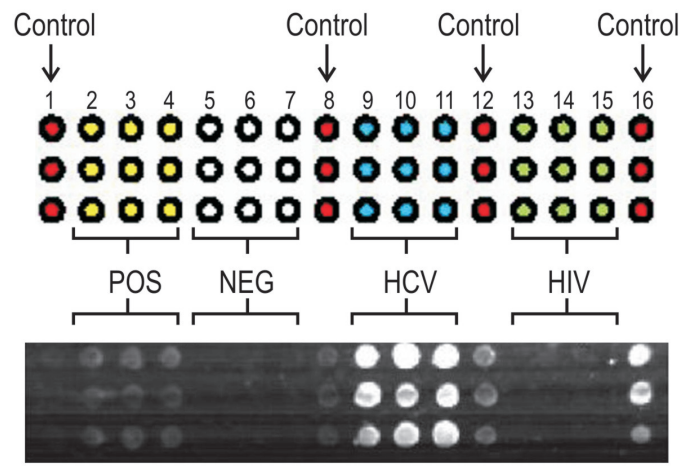

The results obtained showed sensitivity and specificity of $100 \%$ when correlated with previously known results from the serum file of HUPES, which used the ELISA method. In all HTLV positive patients tested, there was no cross-reaction or interference noise in areas sensitized with HIV and HCV specific antigens and controls (Figure 6). The slides 1 and 5 were not blocked during protocol as determined by the procedure; however, this did not change the final results. In the remaining 47 samples, protocol 1 followed regularly, and the result was consistent with the results previously known to the patients (Figures 7 to 10).
Evaluation of Protocols

$\mathrm{PPC} / \mathrm{mBio}$ submitted 38 slides for testing following the protocol 2 . Table 2 summarizes the events with this material.

Thus, of the 38 slides sent, only 13 slides were tested according to the second protocol, which was also compatible with ELISA results, performed shortly after collection from the patients. The lack of blockade in 5 slides during the application of protocol 2 also did not affect the final results (Figures 11a, 11b, 11c - the same patient - and 12a, $12 \mathrm{~b}$ - other patients). Figures 13 to 16 present the results of 13 slides tested according to protocol 2.

Table 2. Occurrences with slides sent by PPC / mBio (protocol 2).

\begin{tabular}{lc}
\hline Events & Slides (N) \\
\hline Lack of slide attachment in Biochip Reader camera & 10 \\
Contamination by fungi & 8 \\
No operation of the device at the time of reading (no signal, background) & 7 \\
\hline Total & $\mathbf{2 5}$
\end{tabular}

Figure 11a. Slide shows HIV positive patient. Lack of blockade the slide during procedure. Signal to gp120 and weak positive controls.

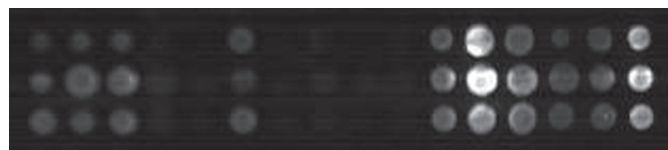


Figure 11b. Slide shows HIV positive patient. Correct use of the protocol (blockade). Signal to gp120 and weak positive controls.

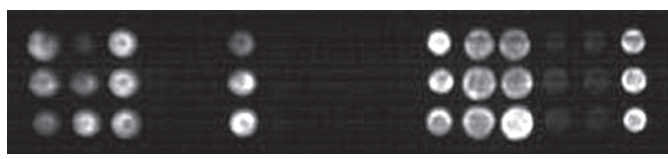

Figure 11c. Slide shows HIV positive patient. Correct use of the protocol (blockade). Normal signal to gp 120.

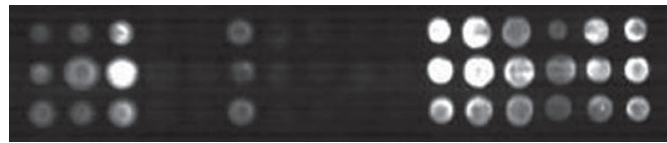

Figure 12a. Slide shows HIV positive patient. Lack of blockade the slide during procedure. Weak signal to gp120.

\begin{tabular}{|c|c|c|}
\hline $\begin{array}{l}900 \\
0 \\
0\end{array}$ & $\begin{array}{l}0 \\
0 \\
0\end{array}$ & $\begin{array}{l}00 \\
000 \\
000\end{array}$ \\
\hline
\end{tabular}

Figure 12b. Slide shows HIV positive patient. Correct use of the protocol (blockade). Normal signal to gp120.

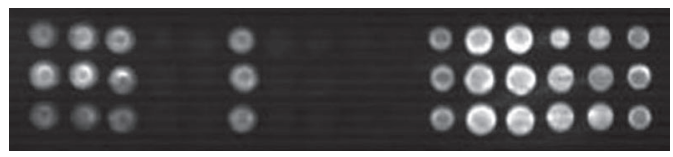

$\underline{\text { Statistical Analysis }}$

Data analysis was performed by BCRanalysis, the software of the Biochip Reader, which analyzed the image points with pre-specific programming by $\mathrm{PPC} / \mathrm{mBio}$, and SPSS Software to calculate median, mean and mode.

\section{Time of Exposure (protocol 2)}

Tests with the exposure time of $50 \mathrm{~ms}$ obtained the best results (Table 3), this being the time of exposure most indicated during this experiment.
Table 3. Time of exposure of slides - mean and mode.

\begin{tabular}{lcc}
\multicolumn{2}{l}{ Time of exposure $(\mathbf{m s}) *$} \\
\hline $\mathrm{N}$ & Valid & 13 \\
& Not valid & 0 \\
Mean & & 57.92 \\
Mode & & 50 \\
\hline \multicolumn{2}{l}{ * } & SPSS software.
\end{tabular}


Figure 13. HIV positive patient. Weak signal to gp120.

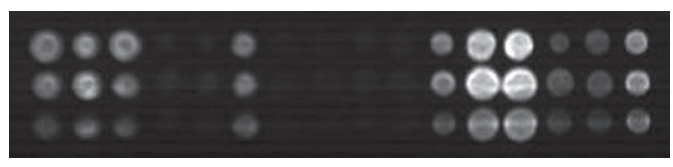

Figure 14. HIV positive patient (coinfected with cytomegalovirus). Weak signal to gp120.

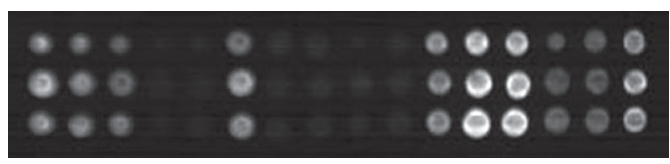

Figure 15. HIV positive patient with disseminated tuberculosis. Backgroung to negative controls and $\mathrm{HCV}$.

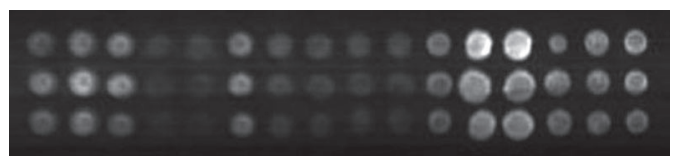

Figure 16. HIV/HCV/HTLV positive patient. Weah signal to gp120 and background to HCV antigens.

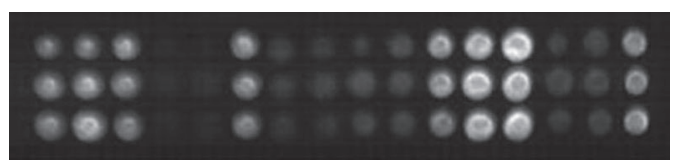

The advances in miniaturization allowed the development of portable systems, electronic and digital components. This development enabled the discovery of the microarray system with the power of simultaneous analysis of thousands of molecules at the same time $[3,8]$, and the improvement of the biosensor. In this study, we describe a Biochip Reader platform for diagnosis that provides a single-sample marker analysis at the same time. The method consists of using a disposable cutting slide integrated with a fluorescence reader based on planar and multimode wave conductors capable of analyzing different tests for detection of specific antibodies (HIV/HCV) at the same time. The sensitivity and specificity were of $100 \%$, without cross-reaction with other known pathogens (HTLV and cytomegalovirus). The tests revealed the ability of the system to maintain the antigen/antibody reaction specific to the researched condition. We also analyzed all the technical steps and procedures, manuals and protocols sent by $\mathrm{PPC} / \mathrm{mBio}$ to obtain the results. 
The results showed the excellent reliability of the system. However, the poor quality of the slide manufactured in the USA may have interfered and affected the experiment carried out in Bahia (UFBA) due to the presence of weak signals, backgrounds in slides or no sharp image in the signal emission, which possibly did not allow good antigen-antibody binding and the action of the fluorophore.

This study emphasized the importance of the quality of the material to be chosen as a substrate for the bioreactor, such as the polishing of the slides [15-16]. Battison (2001) [17] and Vo-Dihn $(1998 ; 2000)$ [18,19] described that substrate polishing is fundamental for good wave conduction and signal emission. As a result, in our study, the poor quality of the slide due to poor polishing of the glass might have impaired and prevented the conduction of the evanescent wave adequately, which was decisive for the presentation of the weak controls, the presence of background and low signal of the antigens for HCV during the use of protocol 2. So, the polishing problems may be related to the imprinting (PPC), causing "dragging" of the molecules during the washing process and subsequently protocol procedures [20].

Also, Monk (2004) [20] and Grace (2011) [16] affirm that for optical systems that use planar wave conductors, they must have their substrate properly polished otherwise they will be unable to conduct the wave and create random or inappropriate signals. According to Feldstein (1999) [21], a fluorescence biosensor, based on planar wave conductors, will work correctly, if the surface of the biochip base (glass, silica or other suitable material) is appropriately polished. This condition may be one of the factors that left all the weak positive controls in the first position, according to protocol 2.

Another problem was the fungus contamination that could occur due to the quality of the slides, transport, and excessive humidity present in our environment or inadequate storage. However, according to Vo-Dihn (2000) [22] and Rowe (2011) [23] biosensors should not have many specifications regarding storage and handling, since the intention is to create a portable and easy handle system.
The slides showed crystal formation and an excess of trehalose, which may be caused by the high temperatures in Brazil [24], which brings the importance of choosing the substrate for the printing of biochips, polishing and pre-blocking with appropriate washes so as not to permit the residue of sugars, which could interfere in the results (backgrounds, inability to signal and read) [7,25].

Notwithstanding, the extremely positive point is that, despite the occurrences in the signals, there was a sensitivity of $100 \%$ in the samples analyzed. Besides, the sera used during the procedures of protocol 1 were old, and this does not seem to change the results. Plasma and serum were also used during the process with protocol 2, and there was no evidence of any change in the results obtained compared to the results using the ELISA method performed concomitantly during this experiment.

The use of two protocols for the tests performed in Bahia occurred due to the emission of more stronger signals in the HIV go 41 region, presenting a "ballooning" of the area for HIV gp41 during the experiment with protocol 1 (Figures 4, 9 and 10). This phenomenon raises doubts as to the right binding in the biomolecules adhered to the spots, because of the overflow which occurred and the bond could occur outside the space previously printed, emitting stronger signals ( $>255 \mathrm{~ms})$, impairing the reading of the slides [26]. This event occurred due to the size of the protein, but it was adjusted in the second protocol to remain no doubt about the results.

The pre-blocking and printing on biomolecule integrated circuits are punctual phases for biochip formation according to Lochhead (2008) [26], Grace (2011) [16] and Macbeath (2000) [27]. Our results showed an excellent pre-blocking performed by $\mathrm{PPC} / \mathrm{mBio}$, since the changes made in the procedures, without the buffering of the slides, did not cause differences in the final result.

The time of exposure is one of the determining factors for the knowledge of sensitivity and specificity in multi-strand-based optical biosensor tests since the amount of $\mathrm{ms}$ is fundamental to the reliability of the experiments [26]. Sometimes it 
is difficult in normalizing the signal of one strand with the sign of another strand in the biosensors due to the differences between optical fibers. This issue is related to the variation of the exposure time to which each fiber is submitted $[25,28,29]$. As each antibody has a specific intrinsic fluorescence, the fluorophores are inserted to stabilize the signal during the analysis $[16,30]$. However, if the exposure time is not "normalized," or preprogrammed on the optical substrate, there will be no stability about exposure time, and this could lead to significant variations in the readings for the same bioreactor [11,12,28,29,31].

So, the time of exposure time was also a critical factor observed in the experiment, since the tests performed with protocol 2 were well below the 255 ms stipulated as a cut-off for reading. During the tests with protocol 2, the best exposure time was $50 \mathrm{~ms}$, without the use of background subtraction and images with $1280 \times 1024$ pixels.

The results obtained for the exposure time also could be related to the limitation of mass transfer instead of a fluorescence transduction signal. The mass transfer has long been recognized as a limitation in this type of microarray system [30,31], which may have led to signal weakening, poor readability, or low exposure time for microarrays in the performance of protocol 2.

Furthermore, data analysis showed that each antigen would require tests at different concentrations in the same blocker and patient serum samples and their dilutions to precisely determine which antigen, blocker, and dilution concentrations of serum samples the experiment should have. It will allow better sensitivity and specificity detection in this multi-analyte format.

Phase II of the study showed good sensitivity and specificity of the system despite the problems presented. More experiments and further improvements are necessary for multi-pathogen detection, which is fast, cost-effective and does not require professional ability to handle the system.

The experiments performed in Brazil showed satisfactory results regarding the performance of the integrated circuit reader system (Biochip Reader) (the PPC/mBio Inc.) in the diagnosis for antibodies against $\mathrm{HIV}$ and $\mathrm{HCV}$, with a sensitivity and specificity of $100 \%$. Nevertheless, adjustments are still necessary to make PPC/mBio's Biochip Reader an efficient, low-cost, portable and easy-to-handle tool. These improvements include larger sampling volume, technical development (slides/trips), optimization of protocols, and standardization of exposure time without large intervals.

\section{Future Perspectives}

The University of San Diego and PPC m/Bio updated the model as a result of the tests carried out in Brazil. This new prototype has more resistant tools; technical improvement of the biosensor, bioreactors, and biochip; and innovative design of slides; better polishing of antigen-specific fixation areas; new lens models and optical filters; fluid channel system more suitable for mass transfer; panel expansion of controls; and a new protocol. Also, the software was adequate and easy to use and handle, with a higher degree of automation and less possibility of manipulation by the user (Figure 17).

PPC and $\mathrm{m} /$ Bio sent the new prototype to Brazil (Figure 18) with the original slides, protocols and faster procedures for validation of tests for HIV, HCV, HBV, T. pallidum and T. gondii. The activities are in progress, and promising results would be obtained for the final stage of the validation of the tests.

Figura 17. A. Model of the wave driver and the new slide. B. Figure of the new Biochip Reader.

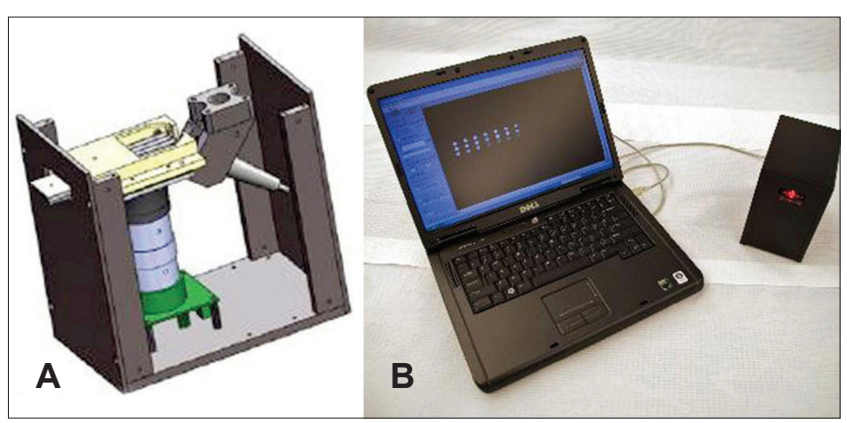


Figure 18. Protocol for using the new slide.

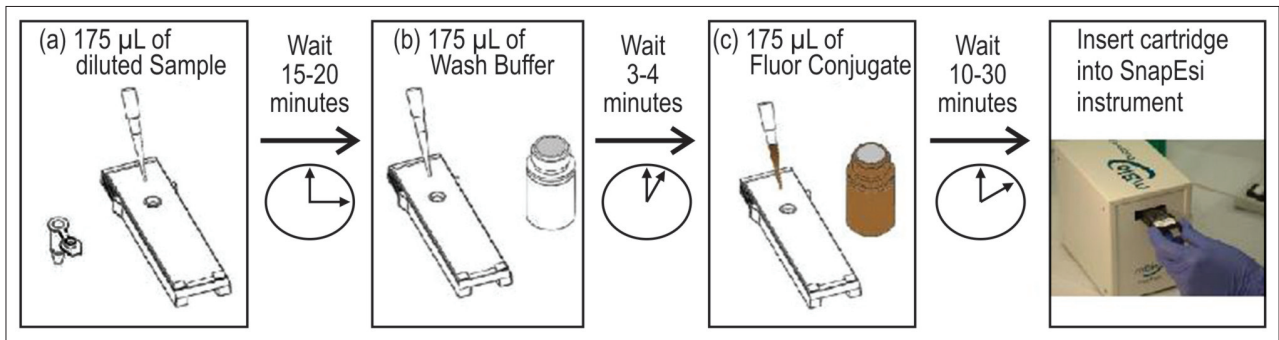

\section{References}

1. WHO. Infectious diseases in all world. Bulletin of the World Health Organization, 2016; v 9, n. 8:545-620.

2. Vaz, A., Takei, K., Bueno, E.C. Imunoensaios: Fundamentos e Aplicações. Rio de Janeiro: Guanabara Koogan, Capítulo 2, 2007.

3. Taitt, C.R. et al. A portable array biosensor for detecting multiple analytes in complex samples. Microb Ecol, 2004;2:175-185.

4. Bakaltcheva, I.B., Shriver-Lake, L.C.; Ligler, F.S. A fiber optic biosensor for multianalyte detection: importance of preventing fluorophore aggregation. Sensors and Actuators B-Chemical, 1998;1-3:46-51.

5. Bakaltcheva, I.B., Shriver-Lake, L.C.; Ligler, F.S. Multianalyte explosive detection using a fiber optic biosensor. Analytica Chimica Acta, 1999;1-2:13-20.

6. Ligler, F.S. et al. The array biosensor: portable, automated systems. Anal Sci, 2007;1:5-10.

7. Albert, K.J. et al. Cross-reactive chemical sensor arrays. Chem Rev, 2010;7:.2595-2626.

8. Narang, U. et al. Multianalyte detection using a capillarybased flow immunosensor. Analytical Biochemistry, 1998;1:13-19.

9. Sapsford, K.E. et al. Kinetics of antigen binding to arrays of antibodies in different sized spots. Analytical Chemistry, 2001;73:5518-5524.

10. Sapsford, K.E. et al. Array biosensor for homeland defense. Abstracts of Papers of the American Chemical Society, 2003;U107.

11. Ligler, F.S. et al. Integrating waveguide biosensor. Analytical Chemistry, 2002;3(713-719).

12. Ligler, F.S. et al. Array biosensor for detection of toxins. Anal Bioanal Chem, 2003;(3): 469-477.

13. Rippel, R.A., Seifalian, A.M. Gold revolution - gold nanoparticles for modern medicine and surgery. J Nanosci Nanotechnol, 2011;May;11(5):3740-8.

14. Pantic, I. Nanoparticles and modulation of immune responses. Sci Prog., 2011;94(Pt 1):97-107.

15. Cha,T.G. et al. Optical nanosensor architecture for cellsignaling molecules using DNA aptamer-coated carbon nanotubes. ACS Nano, 2011;May 24;5(5):4236-44.

16. Grace, K.; Swanson, B. Optical Biosensor Reagentless (ROB). Los Alamos National Laboratory, Los Alamos Biosensor Team, 2011.
17. Battison, F.M. et al. A chemical sensor based on a microfabricated cantilever array with simultaneous resonance-frequency and bending readout. Sens Actuators 2001;77:122131.

18. Vo-Dinh, T. et al. Optical nanosensors for detecting proteins and biomarkers in individual living cells. Clin Diagn Lab Immunol,1998 September;5(5):609-612.

19. Vo-Dinh, T. et al. DNA biochip using a phototransistor integrated circuit.Anal Chem 2000Jan 15;71(2):358-63.

20. Monk, D.J., Walt, D.R. Optical fiber-based biosensors. Anal Bioanal Chem 2004;379:931-945.

21. Feldstein, M.J. et al. Array biosensor: optical and fluidics systems. Journal of Biomedical Microdevices, 1999;1:139-153.

22. Vo-Dinh, T. et al. Biosensors and biochips: advances in biological and medical diagnostics. J Anal Chem 2001;366:540-551.

23. Rowe, C.A. et al. An array immunosensor for simultaneous detection of clinical analytes. Anal Chem, 2011;2:433-439.

24. Ziegler, C. Cantilever-based biosensors. Anal Bioanal Chem 2004;379:946-959.

25. Herron, J.N. et al. Fluorescence Sensors and Biosensors. Taylor \& Francis CRC Press, Boca Raton, FL, 2005:283332.

26. Lochhead, M.J., Delaney, M., Radka, S. et al. Low Cost, Multiplexed Biosensor Technology for Simultaneous Analysis of HIV and Common Co-Infections. AACC Annual Meeting, Vol. Washington, D.C., 2008.

27. Macbeath, G., Schreiber, S.L. Printing proteins as microarrays for high-throughput function determination. Science, 2000;5485:1760-1763.

28. Herron, J.N. et al. Waveguide immunosensor with coating chemistry providing enhanced sensitivity. US Patent, 1996;5(512): 492.

29. Herron, J.N. et al. Planar Waveguide Biosensors for Point-of-Care Clinical and Molecular Diagnostics. In: Thompson RB, ed. Fluorescence Sensors and Biosensors, Vol. Boca Raton, FL: CRC Press Taylor \& Francis Group, 2006.

30. Lee, Y.E., Smith, R., Kopelman, R. Nanoparticle PEBBLE sensors in live cells and in vivo. Annu Rev Anal Chem (Palo Alto Calif), 2009;2:57-76.

31. Kenneth, E. et al. Biomedical Nanostructures JohnWiley\&Sons, Inc. 2010; Chapter 17. 


\title{
Computational Fluid Dynamics Applied to Atherosclerosis Hemodynamics: A Brief Review
}

\author{
Fernanda Sodré*; Alex Álisson Bandeira Santos; Luzia A. Tofaneli; Turan D. Oliveira \\ SENAI CIMATEC, Laboratório de Energia, Salvador, Bahia, Brazil
}

\begin{abstract}
In recent years, Computational Fluid Dynamics (CFD) has been applied to biological systems for the study of physiological properties and the development of new medical devices. It has also been used for the hemodynamic evaluation of care in the diagnosis, treatment, and prevention of cardiovascular diseases. This article presents a brief analysis of the application of Computational Fluid Dynamics in hemodynamics in atherosclerosis, with a review of CFD in the study of blood flow, and in the medical area.
\end{abstract}

Keywords: Computational Fluid Dynamics. Hemodynamics. Atherosclerosis.

Computational Fluid Dynamics (CFD) is a set of numerical methods that obtain solutions to problems involving physical and chemical phenomena of fluid dynamics and heat transfer [1].

CFD has applied only in high technology engineering a few decades ago [2]. However, its use has now expanded to other applications, such as petrochemicals, automotive, aerospace, and medical industries.

The medical field has shown increasing interest in computer simulations because of the ability to reproduce the effects that influence medical diagnoses [3]. There are many advantages of using CFD in the area of health. It is a non-invasive method for research in biological systems, reducing the risks involved in a procedure. Also, it is faster and involves lower costs when compared to experimental and theoretical methods [4,5].

Computational Fluid Dynamics has been applied in different fields of research in several medical areas. Augusto (2014) [6] studied air flow and particle deposition in the pulmonary airways using CFD (Figure 1). Similarly, Kim and colleagues (2013) [7] used the method to simulate airflow inside the nasal cavity.

Received on 18 February 2019; revised 24 February 2019. Address for correspondence: Dr. Fernanda Sodré. Avenida Centro Universitário SENAI CIMATEC; Av. Orlando Gomes, 1845 - Piatã, Zip code: 41.650-010; Salvador, Bahia, Brazil. E-mail: nandacsodre@gmail.

J Bioeng. Biotech. Appl. Health 2019;2(1):15-20.

(C) 2019 by SENAI CIMATEC. All rights reserved.
Figure 1. Velocity areas in the time of air inspiration in the trachea.

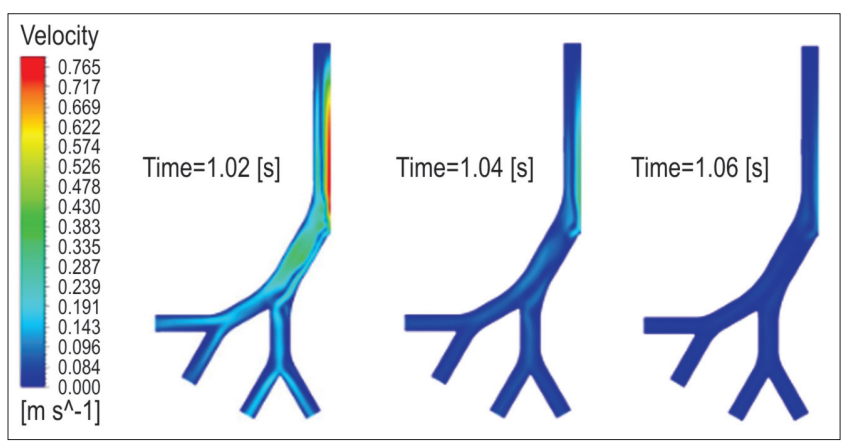

Source: Augusto 2014 [6].

CFD has also been used for the development of medical devices and endoprosthesis. Feurhuberand colleagues [8] used the statistical approach of CFD for steam sterilization tests. The results concluded that the model developed by CFD can predict properties, such as temperature, steam quality; and also the visualization and understanding of the sterilization procedure.

Another significant area is the computational analysis of blood flow. The application of CFD in hemodynamics has featured in several studies, especially those related to cardiovascular diseases, such as atherosclerosis and aneurysms.

Lima and colleagues (2015) [5] and Blessy and colleagues (2016) [9] presented studies that reviewed the application of numerical methods and computational simulations in hemodynamics. The present work aims to demonstrate the relevance of CFD applied to hemodynamics in atherosclerosis through a brief literature review. 


\section{Computational Fluid Dynamics}

Fluid dynamics is based in Navier-Stokes equations, which is conduct by the mass conservation and momentum (Equations - (1) (3)].

$$
\begin{aligned}
& \frac{\partial(\rho u)}{\partial t}+\operatorname{div}(\rho u \vec{u})=-\frac{\partial p}{\partial x}+\operatorname{div}(\mu \quad \operatorname{grad} \quad u)+S_{M x}(1) \\
& \frac{\partial(\rho v)}{\partial t}+\operatorname{div}(\rho v \vec{u})=-\frac{\partial p}{\partial y}+\operatorname{div}\left(\begin{array}{lll}
\mu & \operatorname{grad} & v)+S_{M y}(2)
\end{array}\right. \\
& \frac{\partial(\rho w)}{\partial t}+\operatorname{div}(\rho w \vec{u})=-\frac{\partial p}{\partial z}+\operatorname{div}(\mu \quad \operatorname{grad} \quad w)+S_{M z}
\end{aligned}
$$

$\mathrm{p}=$ pressure $\mathrm{t}=$ time $; \mathrm{x}, \mathrm{y}, \mathrm{z}=$ Cartesian directions; $\mathrm{u}, \mathrm{v}$ and $\mathrm{w}=$ velocities in $\mathrm{x}, \mathrm{y}, \mathrm{z}$ directions (three-dimensional velocity vector); $\mu=$ viscosity of the fluid; $\mathrm{S}_{\mathrm{MX}}, \mathrm{S}_{\mathrm{MY}}, \mathrm{S}_{\mathrm{MZ}}=$ transitory terms in the directions described.

The difficulty in solving the conservation equations analytically for turbulent flow and complex geometry applications requires the application of numerical solutions.

There are 3 different streams of numerical solutions techniques: finite difference, finite element, and spectral methods. The method of finite volume method is central to the most well-established codes, such as CFX/ANSYS, FLUENT, PHOENICS and STAR-CD [10].

Despite using numerical models, the approach of the turbulence phenomena requires the application of turbulence models to reduce computational time. References and theoretic indications frequently used turbulence models (Table 1).

\section{The Use of CFD in Hemodynamics}

Hemodynamics is the study of blood circulation through blood vessels, arteries, veins and capillaries that make up the cardiovascular system [11]. Mathematical models proposed by CFD can simulate the cardiovascular system [12]. The study of CFD in hemodynamics can help to understand what occurs during blood flow. As a result, it could aid in the diagnosis and prevention

\begin{tabular}{|c|c|}
\hline Model & Brief description and equations \\
\hline $\mathrm{k}-\varepsilon$ & $\begin{array}{l}\qquad k=\frac{3}{2}\left[I_{d e f} \max \left(U_{s}, \mid U_{I G}, U_{\omega}\right)\right]_{(4)}^{2} \\
\qquad \varepsilon=\frac{C_{\mu} k^{2}}{v \cdot\left(\mu_{T} / \mu\right)} \\
\text { This model focuses on the } \\
\text { parameters that affect the } \\
\text { turbulence kinetic energy. It is good } \\
\text { to converge. }\end{array}$ \\
\hline $\mathrm{k}-\omega$ & $\begin{array}{l}\quad k=\frac{3}{2}\left[I_{\text {def }} \max \left(U_{S},\left|U_{I G}\right|, U_{\omega}\right)\right]^{2} \\
\qquad \omega=\frac{k}{v \cdot\left(\mu_{T} / \mu\right)} \\
\text { Similar to k-E, but this model has } \\
\text { improved accuracy for internal } \\
\text { flows, and separated flows. } \\
\text { However, this model is hard to } \\
\text { converge, despite more expensive. }\end{array}$ \\
\hline $\mathrm{k}-\omega \mathrm{SST}$ & $\begin{array}{l}\text { Combination of } \mathrm{k}-\varepsilon \text { and } \mathrm{k}-\omega \text {. This } \\
\text { model is difficult to converge. }\end{array}$ \\
\hline
\end{tabular}
of cardiovascular diseases; the identification of
Table 1. Models of turbulence.

hemodynamic properties; the analysis of advanced diseases; surgical procedure and the development of medical devices.

The application ofCFD is based on the following 7 steps: clinical imaging, segmentation and reconstruction, discretization, contour conditions, simulation, post-processing and validation [13].

Medical images provide anatomical and physiological details, which are obtained from ultrasound, computed tomography and magnetic resonance imaging [13]. The conversion of clinical images into geometric models is the base of the segmentation and reconstruction' stages.

Discretization is the production and refinement of the computationalmesh that divides the geometry into volumetric cells. The limit conditions are the physical conditions for the entry, exit, and walls of the model, and the initial parameters and properties of the fluids used.

Computer simulation of cardiovascular system in $3 \mathrm{D}$ consumes time and computational demand. Post-processing is done, such as graphs and tables for analysis, to extract the relevant data. After that, 
the results obtained are analyzed and compared with existing parameters in medicine for validation [13].

An important hemodynamic factor is the viscosity of blood flow. The blood's viscosity can vary according to the applied shear stress. If the strain rate is higher than $100 \mathrm{~s}-1$, which happens in the large arteries, the blood behaves as a Newtonian fluid (constant viscosity). However, if the rate is lower than $100 \mathrm{~s}-1$, the viscosity will present nonNewtonian behavior (variable viscosity) which occurs in the small arteries $[14,15]$.

There are some models for representing the non-Newtonian behavior of blood flow, such as the Casson model, the Carreau model and the Power Law model [12]. A comparison of the viscosity of these models is shown in Figure 2 [12].

Figure 2. Comparison between the viscosity of the Newtonian and non-Newtonian models.

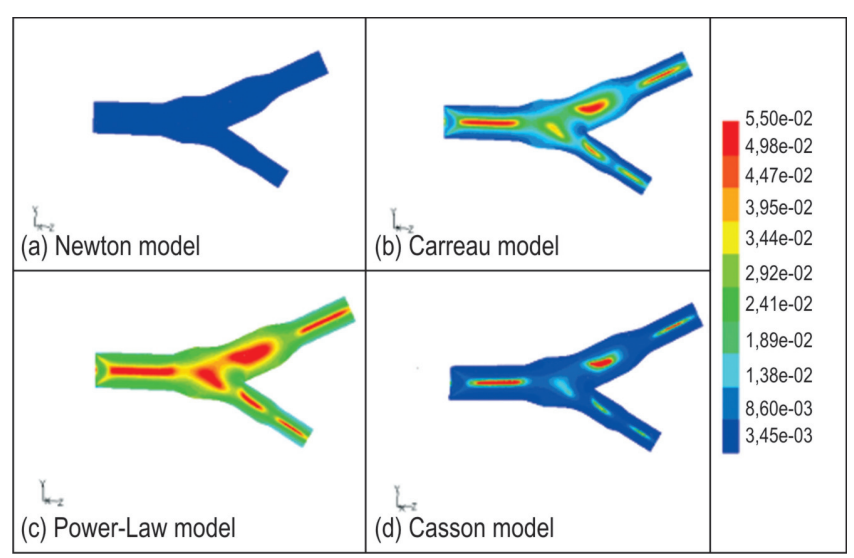

Source: Brambatti (2010) [12].

Tabacow (2014) [16] used CFD in a study of cardiovascular diseases, in which the influence of endoprosthesis on aneurysms through a computational analysis of circulation of blood was analyzed. This result was able to justify the implantation of an endoprosthesis in patients to reduce the degradation of the vessel.

Azevedo (2010) [17], as well as Shishir and colleagues (2015), studied hemodynamic properties in models of saccular aneurysms to understand the pathology (Figure 3).
Figure 3.Types of saccular aneurysms.

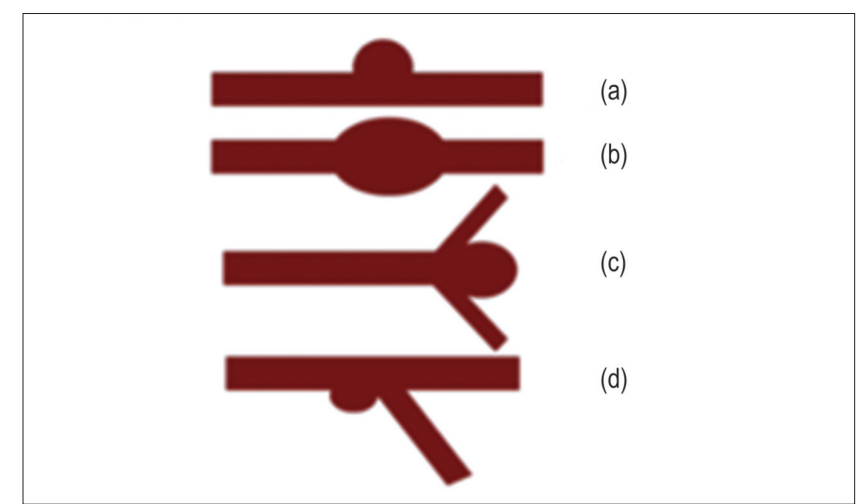

(a) lateral aneurysm; (b) fusiform aneurysm; (c)terminal aneurysm; (d) aneurysm in a bifurcation.

Source: Adapted from Azevedo (2010) [17].

\section{The Use of CFD in Atherosclerosis}

Heart disease is the leading cause of death in the world [19], and atherosclerosis will become the primary source of this disease by 2020 [20].

Atherosclerosis is the result of the deposition and accumulation of fatty-rich and inflammatory substances that accumulate on vessels walls and form atherosclerotic plaques. These events limit the blood flow, causing a narrowing and hardening of the vessels, causing an inadequate supply to vital organs (Figure 4) [21-23].

Atherosclerosis affects regions of complex hemodynamics, such as arterial bifurcations, usually in areas of low shear stress [24]. The shear stress in the vessel walls is one of several

Figure 4. Representation of atherosclerotic plaques on artery walls.

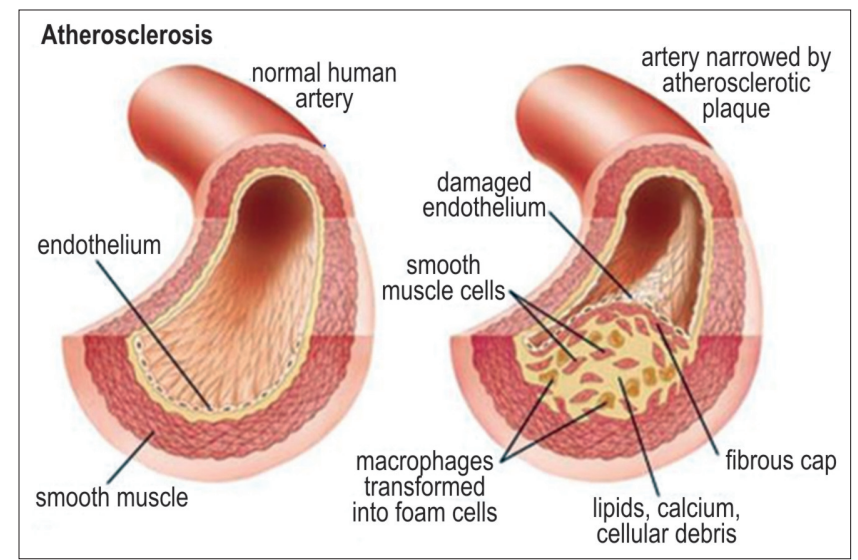

Source: Henriques (2015) [23]. 
hemodynamic factors that are related to the development of the disease [25]. Therefore the identification of these factors could enable early detection and prevention of atherosclerosis [26], as well as help in assessing the severity of stenosis [23].

Computational simulations of atherosclerosis can help in the determination and analysis of these factors, collaborating with the treatment and prevention of the disease. Figure 5 shows the shear stress in the artery with atherosclerosis, showing a tension peak in the existing damage point.

The CFD method has contributed to the therapeutic and surgical planning of the most various cardiovascular diseases [27]. It could also collaborate in the surgical procedures by predicting the results of stenosis. The study developed by Polanzyck and colleagues (2018) [28] is a comparison of before and after surgeries of stenosis through computational simulations and medical examinations. It was possible to use CFD to assist in predicting the outcome of critical stenosis surgeries with a 90\%-98\% accuracy in results [28].

Furthermore, several studies are using CFD for medical devices that aid in the treatment and procedure of atherosclerosis [29-32]. Figure 6 shows the results of the variation in shear stress with a stent implanted in the artery. There has also been research into the development of equipment, such as the analysis developed by Dehlahi and colleagues (2008) [33], which compares the properties of different stent models.

\section{Future Perspectives}

According to Lima and colleagues [5], the implementation of computational methods combined with conventional methods will enable the development of predictive medicine, such as the choice of appropriate surgery based on the comparison between results of computational surgeries performed. Furthermore, the mapping of the physiological properties of atherosclerosis hemodynamics should be done for prevention
Figure 5. Representation of shear stress in a simulation of atherosclerosis.

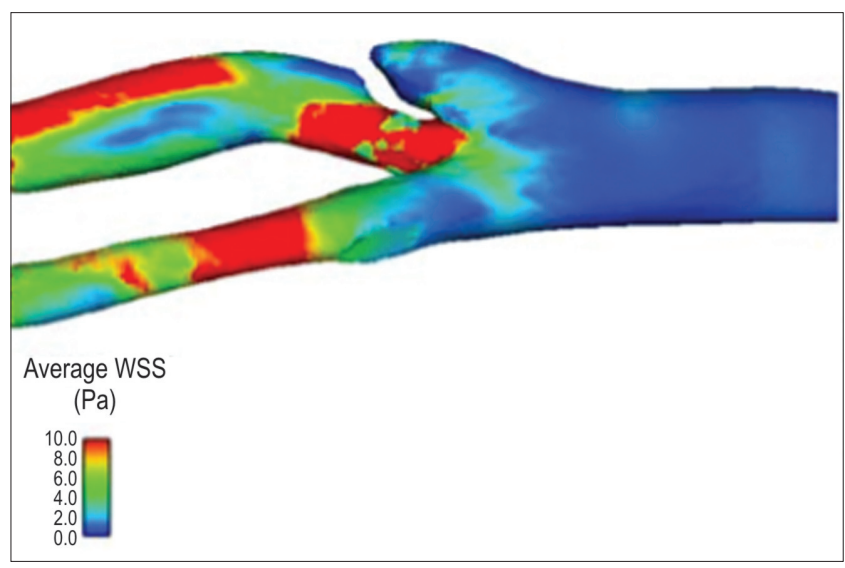

Source: Birchall (2006) [24].

Figure 6. Results of shear stress in simulations of blood models with a stent.

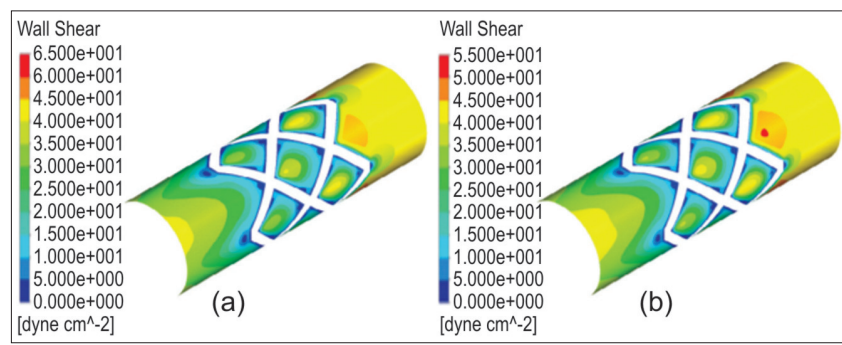

Source:Hsiao(2012) [31].

and diagnosis, as well as the development of technologies and devices for treatments and procedures in the disease.

\section{Conclusions}

Computational Fluid Dynamics can contribute to advances in medicine, especially in the study and analysis of hemodynamics applied to cardiovascular diseases.

However, more studies are needed with CFD applied to medicine to apply this method for other diseases, using new fields of Engineering in Medicine.

\section{Acknowledgments}

SENAI CIMATEC University Center and FAPESB (Foundation for Research Support of the State of 
Bahia) for their financial and technological support in the development of this study.

\section{References}

1. Zikanov, O. Essential Computacional Fluid Dynamics. New Jersey: 2010.

2. Carneiro, A.F.G. C. Influência do Ciclo Cardíaco no Fluxo Sanguíneo na Vizinhaça da Bifurcação Ilíaca.2009. Doctoral thesis in mechanical engineering - University of Minho; 2009.

3. Malecha, Z. et. al. GPU-based simulation of 3D blood flow in abdominal aorta using OpenFOAM. Arch. Mech. 2011;63:137-61. Warszawa - Polônia.

4. Carvalho, J.B. Estudo numérico hemodinâmico de um aneurisma na vizinhança de uma bifurcação arterial tridimensional. Masters dissertation for mechanicalengineering - Universidade Estadual Paulista (UNESP); 2017.

5. Lima, R., Tsubota, K., Wada, S., Yamaguchi, T. Os Métodos Computacionais em Hemodinâmica. ResearchGate. 2015.

6. Augusto, L.L.X. Aplicação da Fluidodinâmica Computacional (CFD) no estudo do escoamento de ar e deposição de partículas em vías aéreas pulmonares. 2014. Masters dissertation for chemical engineering Universidade Federal de São Carlos; 2014.

7. Kim, S.K., Na, Y., Kim, J., Chung, S. Patient specific CFD models of nasal airflow: Overview of methods and challenges. Journal of Biomechanics. 2013;46:229-306.

8. Feurhuber, M., Cattide, A., Magno, M., et al. Prediction of the fluid flow, heat transfer and inactivation of microorganism at medical devices in modern steam sterilizers using computational fluid dynamics. Applied Thermal Engineering. 2017;127:1391-403.

9. Blessy, T., Sumam, K.S. Blood flow in human arterial system-a review. Procedia Technology. 2016;24:339-46.

10. Versteeg, H.K., Malalasekera, W. An Introduction to Computational Fluid Dynamics: The Finite Volume Method. Second edition. Edinburgh Gate: Pearson. 2007.

11. Alves, L.V.S. Otimização da geometria da prótese arterial para intervenção cirúrgica. Porto: Faculdade de Engenharia da Universidade do Porto, 2013.

12. Brambatti, V.M. Utilização da técnica de CFD para simulação do escoamento de sangue em artéria humana. Doctoral thesis in Aerodynamics, Propulsionand Energy - Instituto Tecnológico de Aeronáutica, São José dos Campos; 2010.

13. Morris, P.D., Narracott, A., Tengg-Kobligk, H.V., et al. Computational fluid dynamics modelling in cardiovascular medicine. Heart. 2016;102:18-28.

14. Rabby, M.G., Razzak, A., Molla, Md.M. Pulsatile non-Newtonian blood flow through a model of arterial stenosis. Procedia Technology. 2013;56:225-31.
15. Akbar, N.S., Nadeem, S. Carreau fluid model for blood flow through a tapered artery with a stenosis. Ain Shams Engineering Journal. 2014;5:1307-16.

16. Tabacow, F.B.D. Análise computacional de esforços hemodinâmicos em aneurisma de aorta abdominal infrarenal antes e após a instalação de endopróteses. Masters dissertation for mechanical engineering - Universidade São Paulo (USP); 2014.

17. Azevedo, B.M.C. Estudo preliminar da hemodinâmica em modelos simplificados de aneurismas saculares. Masters dissertation for mechanical engineering - Faculdade de Engenharia da Universidade do Porto; 2010.

18. Shishir, S.S., Miah, Md.A.K., et al. Blood Flow Dynamics in Cerebral Aneurysm - A CFD Simulation. Procedia Engineering. 2015;105:919-27.

19. Roy, M., Sikarwar, B.S., Bhandwal, M., Ranjan, P. Modelling of blood flow in stenosed arteries. Procedia Computer Science. 2017;115:821-30.

20. Fauci, A.S., Braunwald, E., Kasper, D., et. al. Harrison's principles of internal medicine. 2008. 17.a ed. NewYork: McGrawHill.

21. Silva, H.J.G. Caracterização do fluxo sanguíneo duma Bifurcação da Artéria Carótida com Estenose. Masters dissertation for mechanical engineering - Faculdade de Engenharia da Universidade do Porto; 2015.

22. Kumar, S., Deoghare, A.B. Modelling of Human Abdominal Artery for Blood flow Analysis. Materials Today: Proceedings. 2018;5:12877-85.

23. Henriques, H.A.M. Caracterização do fluxo sanguíneo de uma bifurcação da artéria carótida comum com estenose. Masters dissertation for Biomedical engineering Universidade do Porto; 2015.

24. Birchall, D., Zaman, A., Hacker, J., Davies, G., Mendelow, D. Analysis of haemodynamic disturbance in the atherosclerotic carotid artery using computational fluid dynamics. EurRadiol. 2006;16:1074-83.

25. Chen, J., Lu, X. Numerical investigation of the nonNewtonian pulsatile blood flow in a bifurcation model with a non-planar branch. Journal of Biomechanics. 2006;39:818-32.

26. Chaichana, T., Sun, Z., Jewkes, J. Computation of hemodynamics in the left coronary artery with variable angulations.Journal of Biomechanics. 2011;44:1869-78.

27. Feijó, R. Projeto de pesquisa e desenvolvimento do LNCC/MCT em modelagem e simulação computacional do sistema cardiovascular humano. Laboratório Nacional de Computação Científica (LNCC). Petrópolis - 2004.

28. Polanzyck, A., Podgorski, M., Wozniak, T., Stefanczk, L., Strzelecki, M. Computational fluid dynamics as an engineering tool for the reconstruction of hemodynamics after carotid artery stenosis operation: a case study. Medicina. 2018;54(42).

29. Contim, M., Long, C., Marconi, M., et al. Carotid artery hemodynamics before and after stenting: A patient specific CFD study. Computers \& Fluids. 2016;141:62-74. 
30. Santos, G.B. Hemodynamic changes in intracranial aneurysms due to stent-induced vascular remodeling. Masters dissertation for mechanical engineering - Universidade Estadual Paulista; 2018.

31. Hsiao, H., Lee, K., Liao, Y., Cheng, Y. Hemodynamic simulation of intra-stent blood flow. Procedia Engineering. 2012;36:128-36.
32. Dehlahi, V., Tafazoli, S., Najarian, S. Analysis of wall shear stress in stented coronary artery using 3D computational fluid dynamics modeling. Journal of materials processing technology. 2008;197:174.

33. Li, Y., Zhang, M., Verrelli, D.I., et al. Numerical simulation of aneurysmal haemodynamics with calibrated porous-medium models of flow-diverting stents. Journal of Biomechanics. 2018;80:88-94. 


\title{
Study of Medical-Assistance Equipment, Orthotics, Prosthetics, and Special Materials in the Unified Health System (SUS) in Brazil
}

\author{
Fotini Santos Toscas*; Thiago Rodrigues Santos; Eduardo Jorge Valadares Oliveira \\ Ministry of Health; Brasilia, DF, Brazil
}

\begin{abstract}
Medical Assistance Equipment (MAE), Orthotics, Prosthetics and Special Materials (OPSM) are strategic subsectors of the Industrial Health Complex (IHC).The dynamism and peculiar characteristics of these technologies characterize the innovation field and the short life cycle of technological developments. The study aims to consolidate the products in a single list by analyzing computerized databases and consulting the technical and other areas in the Ministry of Health. The study strengthens the data obtained and investigates the repeated items in the adopted criteria, crossing this information with previous publications. We established standards about MAE and OPSM in this study that have already been repeated in previous publications. Thus, there is a concentration of skills needs for these technologies in industrial and technological development, as well as in technological services requirement of these products.
\end{abstract}

Keywords: Equipment Approval. Diagnostic Equipment. Biomedical Technology Assessment. Unified Health System (SUS).

Medical Assistance Equipment (MAE) and Orthotics, Prosthetics and Special Materials (OPSM) are strategic subsectors of the Industrial Health Complex (CIS / IHC). The dynamism and particular characteristics of these technologies characterize the innovation environment, and their short technological life cycle, in addition to the relevance in health services and representativeness in technological and industrial development. According to the World Health Organization (WHO), the health products sector comprises more than 10 thousand categories of products and about 1.5 million different items. This broad range of products varies from low levels of technological intensity and high technological complexity.

The health care industry is one of the most dynamic sectors of the world economy, with an estimated annual turnover of $\$ 350$ billion in 2014 , with about 30,000 industries around the world, and more than 1 million employees. Brazil is the 7th largest market in the world, accounting for about $5 \%$ of the country's total health expenditure

Received on 10 February 2019; revised 10 March 2019.

Address for correspondence: Fotini Toscas. Deciis/SCTIE/ MS. Ministério da Saúde, Brasília, DF, Brazil. E-mail: fotini. toscas@saude.gov.br

J Bioeng. Biotech. Appl. Health 2019;2(1):21-26

C 2019 by SENAI CIMATEC. All rights reserved. and earning about the US \$ 11.7 billion in 2014 [1]. It is a future-bearing industry, as it is a source generating innovations incorporating technological advances in addition to the dynamic interrelations in the scope of IHC and the economy sector [2].

In the public sphere, the Ministry of Health promotes the MAE and OPSM's market for the acquisition of these technologies through transfers to public and private non-profit institutions, linked to the Unified Health System (SUS - Sistema Único de Saúde), as well as in the reimbursement of procedures that use these products for health.

Decentralization of public health management and resources is one of the guidelines of SUS. The procedure of the needs is upward, from the local to the federal level, following deliberative agencies and consistent with the requirements of the health programs and the budget available. As a result of the acquisition of health products predominantly occurs in a decentralized manner, where each agency is responsible for purchasing services, such as OPSM and MAE individually, using their bidding processes. Decentralized purchasing spreads available resources keeping track of the government purchasing power. On the other hand, the centralized acquisition process is difficult, because it requires the analysis of several technical and operational aspects, such as agreement among the subjects involved, 
planning, priorities, definitions of specifications and technical descriptions, technological design, cost analysis, acquisition, distribution/logistics, training, operation management, disposal and reverse logistics.

The Ministry of Health makes a constant effort to provide health units with the installation of new equipment. Most of this spending is on MAE, from the most straightforward needs of a Basic Health Unit (SUS) or Emergency Care Unit (ECU ( UPA) to the most sophisticated for health units and hospitals of medium and high complexity.

Currently,the health care of the population requires the use of some of these technologies, despite the fact that the emphasis is still on primary care, such as the Family Health Care Program (FHCP / PSF) or the Basic Health Units (BHU / UBA), in which MAE of low complexity are contemplated and indispensable for clinical procedures. Thus, the use of these technologies is a valuable tool to provide efficient care to the patient [3].

The main aim of this study presents an review study based on the databases of the computerized systems of the Ministry of Health (Information and Management System for Equipment and Materials (IMSEM /SIGEM) of National Health Fund (NHF ( FNS) and the Department of Informatics of SUS (DATASUS) for the year 2017, to identify the multiplication of MAE and OPSM in Brazil.

The searching was carried out in the following computerized systems of the Ministry of Health: SIGTAP - System of Management of the Table of Procedures, Medications, and OPM of SUS [4] and SIGEM - System of Management of Durable Equipment and Permanent Materials for SUS [5]. We search the data on the CONITEC portal - National Commission for the Incorporation of Technologies in SUS [6]. The research was also carried out in the ECRI database - Emergency Care Research Institute [7]. The study used a qualitative approach, starting from an analysis review in official documents of the Secretariat of Science, Technology and Strategic InputsSCTIE of the Ministry of Health-MS, related to the IHC and the strategic product lists. The available databases were used to search for market information and competitiveness of the health products industry.

The objective of the study is to consolidate the products in a single list by analyzing the computerized databases and consulting the technical areas of the Ministry of Health, in addition to cross-referencing information with previous publications of priority products. The first phase of the study was to search the National Report of Permanent Equipment and Materials (NRPEM/ RENEM) that can be financed by the Ministry of Health in 2016. We classified the items for diagnosis, therapy, and rehabilitation in this phase of research. We did not consider medical assistance, infrastructure, furniture, mobile units, vehicles, and computers in the study. The items delimited in the research were as following:

I Incidence: The aspects were selected based on in the approved quantitative, in which the proposals of investment projects were superior to 500 units in number and with a total value superior to $R \$ 1,000,000.00$. The study returned 16 items with these criteria. Total Value: The items were selected based on in the approved quantitative, in which the proposals of investment projects were higher than R \$1,000,000.00 regardless of the amount permitted. The study returned 58 items with these criteria.

II Unit Value: Items verified that the maximum allowed values for registration of investment projects were higher than $\mathrm{R} \$ 300,000.00$. Returned 36 items in this criterion.

The second phase of the study sought data on incorporation and Judicial Process:

I. Incorporation: MAE and OPSM chosen were selected and incorporated into the SUS procedures table by the National Commission for the Incorporation of Technologies into SUS (Conitec) and FNS, from 2013 to 2016. The study returned 32 items using these criteria.

II. Judicial Process: MAE and OPSM that 
needed a lawsuit in 2015 and 2016. The study included the items that are in legal proceedings underway in the Ministry of Health. The study returned 21 items in the judicial process.

In consultation with the final and technical areas of the Secretariat of Health Care - SAS and the Executive Secretariat of the Ministry of Health, the following data were collected:

I. Mapping of Care Requirements: In the first quarter of 2017, the Ministry of Health provided an Electronic Form (FormSUS) for the Health Services to indicate their needs in MAE, through the Health Care Secretariat (SAS). The study considered the data obtained in the mapping of health care demand and verified 22 items.

II. ABC Curve of OPSM: The Executive Secretariat of the Ministry of Health, through the Department of Health Economics, prepared an internal study containing the ABC curve of 100 procedures related to the use of OPSM. Our study considered a hundred items identified on the ABC curve.

Finally, the study considered international data, using the information from the list published in 2017 by the ECRI Institute of 10 medical technologies of most significant risk. This research reviewed the nomenclature and classification available in RENEM and SIGTAP of the Ministry of Health, due to that there is no standardization of item nomenclatures.

\section{Results and Discussion}

The study consolidated the data obtained to formulate a single list, and analyzed the items that were repeated in the criteria adopted. The final list was 192 consolidated items, with 20 issues appearing in three principles, described below in the study phases (emphasis on diagnostic imaging equipment, in vitro and in vivo diagnostic analyzers, cardioverter/defibrillator, anesthesia machine, video endoscopy and laparoscopy system, electric scalpel, diagnostic ultrasound, catheter, stents and prosthesis for cochlear implant). In four criteria appeared the multi-parameter monitor and the wheelchair, as well as pulmonary ventilator (Table 1).

The study considered all the criteria with the same relevance.

Table 1. Items using at least three criteria.

In vitro and in vivo diagnostic analyzer

Anesthesia Machine

X-ray Machine

Electric scalpel

Wheelchair

Cardioversion / Defibrillator

Catheters/Balloon catheter for peripheral angioplasty

Mammograph

Multiparameter Monitor

Prosthesis for cochlear implant

Flexible Video Endoscopy System

Video System Laparoscopy / Rigid Endoscopy

Coronary / pharmacological / non-covered stent

Computerized Tomography

Optical Coherence Tomography

Ultrasound

Pulmonary Ventilator

The study crossed the information with the previous publications with the theme of prioritization of equipment and materials for health. The publications observed:

i) list of priority equipment of Government Order No. 978/2008 of the Ministry of Health [8];

ii) Priority medical products defined after the crossing of SAS and ABIMO information from the study carried out by Eduardo Jorge Oliveira Valadares in 2010 [9];

iii) List of strategic products for the SUS of Ministry of Health Decree No. 3,089 / 2013 [10];

iv) List of strategic products for the SUS of the Ministry of Health Administrative Order No. 2.888 / 2014 [11]. Table 2 presents the list with the cross-referencing of the information found in the publications. 
Table 2. List of cross references.

\begin{tabular}{|c|c|c|c|c|}
\hline Item & $\begin{array}{c}\text { Government } \\
\text { Order } 978 / 2008 \\
\end{array}$ & $\begin{array}{c}\text { Oliveira, } \\
2010 \\
\end{array}$ & $\begin{array}{c}\text { Government } \\
\text { Order } 3,089 / 2013 \\
\end{array}$ & $\begin{array}{c}\text { Government } \\
\text { Order } 2,888 / 2014 \\
\end{array}$ \\
\hline $\begin{array}{l}\text { In vitro and in vivo } \\
\text { diagnostic analyzer }\end{array}$ & $\mathrm{x}$ & $\mathrm{x}$ & $\mathrm{x}$ & \\
\hline Anesthesia Machine & $\mathrm{x}$ & $\mathrm{x}$ & $\mathrm{x}$ & \\
\hline X-ray Machine & $\mathrm{x}$ & $\mathrm{x}$ & $\mathrm{x}$ & \\
\hline Electric scalpel & & & $\mathrm{x}$ & \\
\hline Wheelchair & & & $\mathrm{x}$ & \\
\hline Cardioversor / Defibrillator & $\mathrm{x}$ & $\mathrm{x}$ & $\mathrm{x}$ & $\mathrm{x}$ \\
\hline $\begin{array}{l}\text { Catheters / Balloon catheter } \\
\text { for peripheral angioplasty }\end{array}$ & $\mathrm{X}$ & $\mathrm{x}$ & $\mathrm{X}$ & \\
\hline Mammograph & $\mathrm{x}$ & $\mathrm{x}$ & & \\
\hline Multiparameter Monitor & $\mathrm{x}$ & & $\mathrm{x}$ & $\mathrm{x}$ \\
\hline Prosthesis for cochlear implant & & & $\mathrm{x}$ & $\mathrm{x}$ \\
\hline $\begin{array}{l}\text { Flexible Video Endoscopy } \\
\text { System }\end{array}$ & $\mathrm{x}$ & $\mathrm{x}$ & $\mathrm{x}$ & \\
\hline $\begin{array}{l}\text { Video System Laparoscopy / } \\
\text { Rigid Endoscopy }\end{array}$ & $\mathrm{x}$ & $\mathrm{x}$ & $\mathrm{x}$ & \\
\hline $\begin{array}{l}\text { Coronary / pharmacological / } \\
\text { non-covered stent }\end{array}$ & $x$ & $x$ & $\mathrm{X}$ & $\mathrm{x}$ \\
\hline Computerized Tomography & & $\mathrm{x}$ & & \\
\hline Optical Coherence Tomography & & & $\mathrm{x}$ & \\
\hline Ultrasound & $\mathrm{x}$ & $\mathrm{x}$ & $\mathrm{x}$ & \\
\hline Pulmonary Ventilator & $\mathrm{x}$ & $\mathrm{x}$ & $\mathrm{x}$ & \\
\hline
\end{tabular}

Maldonado and colleagues (2013) present examples of priority equipment necessary to build competencies:

i) dedicated chips for the hospital equipment industry, which can be used in numerous electromedical equipment;

ii) hemodialysis: filters used in hemodialysis;

iii) surgical articles and instruments made from engineering plastics - not by traditional methods of metallurgical industries;

iv) automated diagnostic equipment;

v) medical imaging: receptors, ultrasound devices, digital radiology; and

vi) material technology [2].

Landim and colleagues (2013) studied four segments of medical devices to detail aspects of the structure and the competitive dynamics of the sector. The selected sections were: in vitro diagnosis, diagnostic imaging, implants and electromedical. The study showed the following opportunities: directing efforts to internalize the assembly of smaller equipment, internalizing technologies for the manufacture of reagents for higher value-added tests, and stimulating the development and production of tests in the country. For imaging equipment, the study indicates that six devices were responsible for about $15 \%$ of the entire medical equipment sector deficit in 2012 (Magnetic Resonance Imaging, Ultrasound Imaging, Computed Tomography, Lightning Tubes X, Angiograph and Mammograph). In the implants segment, the study evaluated orthopedic and cardiovascular implants, with emphasis on the development of new materials, such as bioabsorbable and miniaturization of implants with embedded electronics. Finally, electromedical items, with focus on ventilators 
and vital signs monitors, the study indicates the use of remote monitoring through Information and Communication Technology, as well as the use of bright surgical rooms with integrated systems [12].

\section{Conclusion}

MAE and OPSM identified in this study have been corroborated in previous publications. Of the seventeen items identified as a priority in 2017 , twelve were included in the 2008 list of strategic products. This fact shows a concentration of skills needs for these technologies in industrial and technological development, as well as in the technologic services that these products require. The study also presents the peculiar characteristics of the market with a tendency to conglomerates and oligopolies. With recent and intense acquisitions, in particular, in the subsector of diagnosis by imaging and electromedical life support, small and medium-sized national companies focus on the innovation process and competitiveness level in the external market. These changes in the market have a significant impact on the supply and diffusion of these technologies. Several efforts have been made to mitigate technological vulnerability and also to minimize technological assistance gaps. The plan to expand radiotherapy is an example, through the state's purchasing power, not only increased bargaining power in the procurement process but also increased the national productive and technological system through technological compensation.

As a future perspective, technological relevance will be the tools to solve challenges and also strengthen the purchasing power of the State is highlighted. The new Framework for Science, Technology, and Innovation, with Law number 13,243/2016, establishes that "public administration organizations, according to public interested, can directly contract ICT, non-profit private organizations or companies, individually or in consortiums, focused on research activities and recognized technological qualification, aiming to carry out research, development and innovation activities that involve technological risk, in order to solve specific technical problem or obtain product, service or process innovation" [13]. Still pending regulatory aspects, the technological view presents itself as a strategic tool to increase the use of the purchasing power of the State. State purchasing power is crucial to ensure the maximization of available resources and the expansion of health benefits, together with the knowledge of decisions that are required by a universal health system.

\section{References}

1. Abimed. Associação Brasileira da Indústria de Alta Tecnologia de Produtos para Saúde. Business Review Brasil e Healthcare Global.[Internet]. 2015 [acesso 10 out 2017]. Disponível em: http://intranet.abimed.org. br/noticias.aspx.

2. Maldonado, J, Gadelha CAG, Vargas, M, Costa, LS, Quental, C. O subsistema de base mecânica, eletrônica e de materiais do complexo econômico industrial da saúde: perspectivas para 2022/2030. Rio de Janeiro: Fiocruz/Ipea/Ministério da Saúde/Secretaria de Assuntos Estratégicos da Presidência da República, 2013. Vol.5.pp.81-117.ISBN 978-85-8110-019-7.

3. Brasil. Ministério da Saúde. Secretaria Executiva. Departamento de Economia da Saúde, Investimento e Desenvolvimento. Secretaria de Ciência, Tecnologia e Insumos Estratégicos. Departamento de Ciência e Tecnologia. Mapeamento e diagnóstico da gestão de equipamentos médico-assistenciais nas regiões de atenção à saúde do projeto QualiSUS-Rede/Ministério da Saúde, Secretaria de Ciência, Tecnologia e Insumos Estratégicos, Departamento de Ciência e Tecnologia. - Brasília: Ministério da Saúde, 2016.

4. Brasil. Sistema de Gerenciamento de Equipamentos e Materiais Permanentes Financiáveis para o SUS. [Internet]. 2017 [acesso 10 out 2017]. Disponível em: http://www.fns.saude.gov.br/visao/ pesquisarEquipamentos.jsf.

5. Brasil. Sistema de Gerenciamento da Tabela de Procedimentos, Medicamentos e OPM do SUS. [Internet]. 2017 [acesso 10 out 2017]. Disponível em: http://sigtap.datasus.gov.br/tabela-unificada/app/sec/ inicio.jsp.

6. Brasil. Comissão Nacional de Incorporação de Tecnologias no SUS. [Internet]. 2017 [acesso 10 out 2017]. Disponível em: http://conitec.gov.br/.

7. ECRI. Emergency Care Research Institute. [Internet]. 2017 [acesso 10 out 2017]. Disponível em: https://www. ecri.org/Pages/default.aspx. 
8. Brasil. Portaria $\mathrm{n}^{\circ} 978$, de 16 de maio de 2008 , que dispõe sobre a lista de produtos estratégicos, no âmbito do Sistema Único de Saúde, com a finalidade de colaborar com o desenvolvimento do Complexo Industrial da Saúde e institui a Comissão para Revisão e Atualização da referida lista.

9. Oliveira, E.J.V. "Engenharia clínica aplicada à definição e Implementação de uma proposta desenvolvimentista para o sistema nacional de inovação de produtos médicos". Campinas, SP:[s.n],2010.

10. Brasil. Portaria $n^{\circ} 3.089$, de 11 de dezembro de 2013, anexo com a lista de produtos estratégicos para o Sistema Único de Saúde (SUS).

11. Brasil. Portaria $n^{\circ} 2.888$, de 30 de dezembro de 2014, que define a lista de produtos estratégicos para o Sistema Único de Saúde (SUS), nos termos do anexo a esta Portaria.
12. Ladin.A., Gomes.R., Pimentel.V., Reis. C., Pieroni.J.P. Equipamentos e tecnologias para saúde: oportunidades para uma inserção competitiva da indústria brasileira.

Banco Nacional de Desenvolvimento Econômico e Social. Brasil, 2013.

13. Brasil. Lei $\mathrm{n}^{\mathrm{o}} 13.243$, de 11 de janeiro de 2016, que dispõe sobre estímulos ao desenvolvimento científico, à pesquisa, à capacitação científica e tecnológica e à inovação e altera a Lei no 10.973, de 2 de dezembro de 2004, a Lei no 6.815, de 19 de agosto de 1980, a Lei no 8.666, de 21 de junho de 1993, a Lei no 12.462, de 4 de agosto de 2011, a Lei no 8.745, de 9 de dezembro de 1993, a Lei no 8.958, de 20 de dezembro de 1994, a Lei no 8.010, de 29 de março de 1990, a Lei no 8.032, de 12 de abril de 1990, e a Lei no 12.772, de 28 de dezembro de 2012, nos termos da Emenda Constitucional no 85, de 26 de fevereiro de 2015 . 


\title{
Maintenance Management in a Health Care Establishment
}

\author{
Fabricio Avelino Bispo*; Marinilda Lima Souza; Sérgio Pitombo \\ Centro Universitário SENAI CIMATEC; Salvador, Bahia, Brazil
}

\begin{abstract}
With the accelerated growth of the health area in Brazil, institutions increasingly seek to optimize the operations by leveraging the results and becoming competitive in the market. Ensuring the high availability of infrastructure and assets provides that the organization is a strategic tool to achieve positive productivity results. However, it is necessary to structure the engineering department of the maintenance and correct administration of the flows that integrate the sector to meet the expected results. The use of computerized maintenance control tools helps in the management of environments and equipment, assuring the operational reliability of the health care establishment. This article presents the stages of implementation of management and maintenance in a health care establishment. The results demonstrate the evolution in the control of the maintenance department with greater efficiency, planning, increased availability of infrastructure and equipment as well as reduced costs for the operation of health sector processes in Brazil.
\end{abstract}

Keywords: Maintenance Management. Assets. Maintenance Software. Availability. Reliability.

Healthcareorganizationsareseekingalternatives to reduce costs in their operations and optimize production to ensure sustainability with the use of new technologies and the high competitiveness in the market. Some factors affect and interfere in the patient expectations to care to receive according to Establishing Health Outreach (EHO) [1]. For such reasons, EHO needs to be organized to ensure full recovery of the patient's condition. It is essential to provide the operability of the infrastructure and medical equipment to maintain the quality of the provision of services in a healthcare establishment. Intervention management of assets should be carried out correctly and in an organized manner. The maintenance department is essential for ensuring the availability and reliability of equipment and installations. It provides the quality of the final product, making it a strategic sector in a health care setting. This article presents the implementation of a maintenance management program in a healthcare establishment through the application of maintenance management software.

Received on 21 February 2019; revised 8 March 2019.

Address for correspondence: Dr. Fabricio Avelino Bispo. Centro Universitário SENAI CIMATEC. Avenida Orlando Gomes, 1845 - Piatã; Salvador, Bahia, Brazil. E-mail: fabricioavelino1@yahoo.com.br.

J Bioeng. Biotech. Appl. Health 2019;2(1):27-33

(C) 2019 by SENAI CIMATEC. All rights reserved.

\section{Maintenance Management of Hospital Equipment}

Slack and colleagues (2004) [2] classify the following objectives of maintenance: higher product quality, cost reduction, greater safety, better work environment, longer equipment life and, the most important of all, higher reliability of equipment. An effective maintenance management system is one that consists of the elaboration and fulfillment of a maintenance plan. This plan will enable the company to achieve profitability and survival goals with equipment, which not fail nor impair the quality, cost, and delivery of products and services and does not jeopardize the safety and integrity of the environment [3]. The current demands of the area of maintenance of healthy environments should have strategies to improve the safe use of equipment, reduce operating costs and seek guidance in documents from the Ministry of Health [4]. The healthcare environment should be kept in constant operation, adopting best practices and running healthy and environmentally responsible places.

We analyzed the implementation of a maintenance management system, the Smart Clin, software available in health care establishments. The steps of deploying the software involved planning, data collection, and data analysis, implementation of a preventive maintenance plan, training, operation and interpretation of 
results guided by the PDCA cycle. These steps are a management tool that the goal is to promote continuous improvement of processes using four actions: Plan, Carry out the plan, Check and Act.

\section{Case Report}

The present case study was carried out in a leading company for the provision of imaging diagnosis healthcare services, located in the state of Bahia. Maintenance management software was implemented to map, organize and manage the processes of the department. The planning for project development initiated in the second half of 2016 and the analyzed data correspond to 2017. The financial results of the department were compared to evaluate the effectiveness of the project. It is noteworthy that the establishment did not have a defined and organized maintenance department, so the demands were solved as they were identified in the EHO operation routine. There was no control over procedures, cost management and/or application of labor in the maintenance area.

\section{Smartclin Software}

TheSmartClinSoftware is a tool for managing services in health units. It consists of several application modules such as supplies, invoicing, human resources and care. Among the modules available, the module "Manut" is for maintenance management and had been inactive in the EHO due to the lack of administration of the department. It is noteworthy that the results of the project were analyzed in the monthly costs of maintenance of building infrastructure and support equipment.

PDCA cycle was used for the implementation of management and software. Figure 1 illustrates the PDCA cycle.

During the planning stage, the following maintenance system objectives were defined:

- Control of preventive maintenance of the building;

- Control of preventive maintenance of support equipment (refrigeration, air-conditioning, generators, etc.);
Figure 1. PDCA cycle.

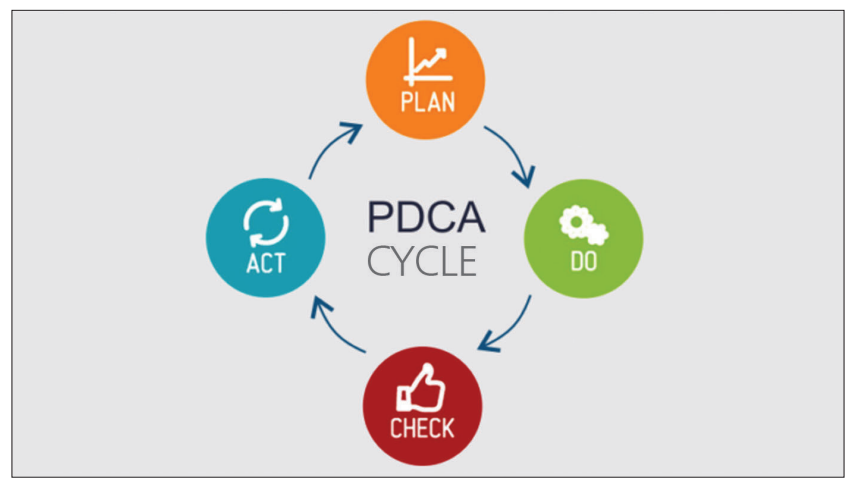

Source: Filho, G.B. (2005)

- Control of corrective maintenance in equipment and infrastructure;

- Define the sector flowchart.

We developed action plans to achieve these objectives through the $5 \mathrm{~W} 2 \mathrm{H}$ tool. A management tool allowed to organize actions and distribute activities to have a specific result, usually used in a spreadsheet or table format. It consists of 7 questions in English of which 5 start with $\mathrm{W}$ and 2 start with $\mathrm{H}$, as follows:

- Why? - Why is it done?

- What? - What will be done?

- Where? - Where will it be done?

- When? -When will it be done?

- Who? - Who will it be done?

- How? - How will it be done?

- How Much? - How much it will be cost?

\section{Managing EHO Maintenance}

Macros' tasks were registered for system implementation in the plan of action, as well as the process model and the main activities called flowcharts. The goal of the diagrams (Figures 2 and 3) was to show the team and the department how the maintenance department can meet its internal and external clients with all the steps required to complete a specific task. The flowchart in Figure 2 illustrates the steps of planning, execution, and control of preventive maintenance. 
Figure 2. Preventive maintenance flowchart.

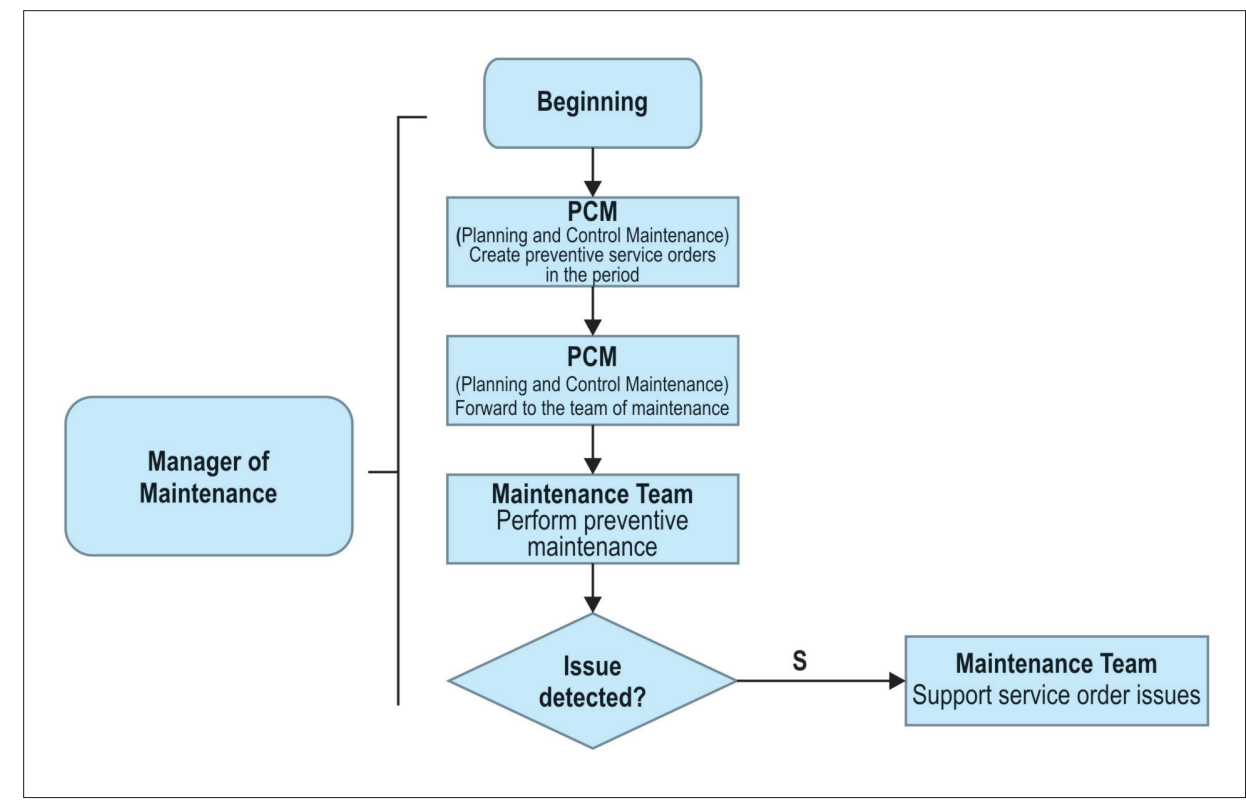

Figure 3. Flowchart corrective maintenance.

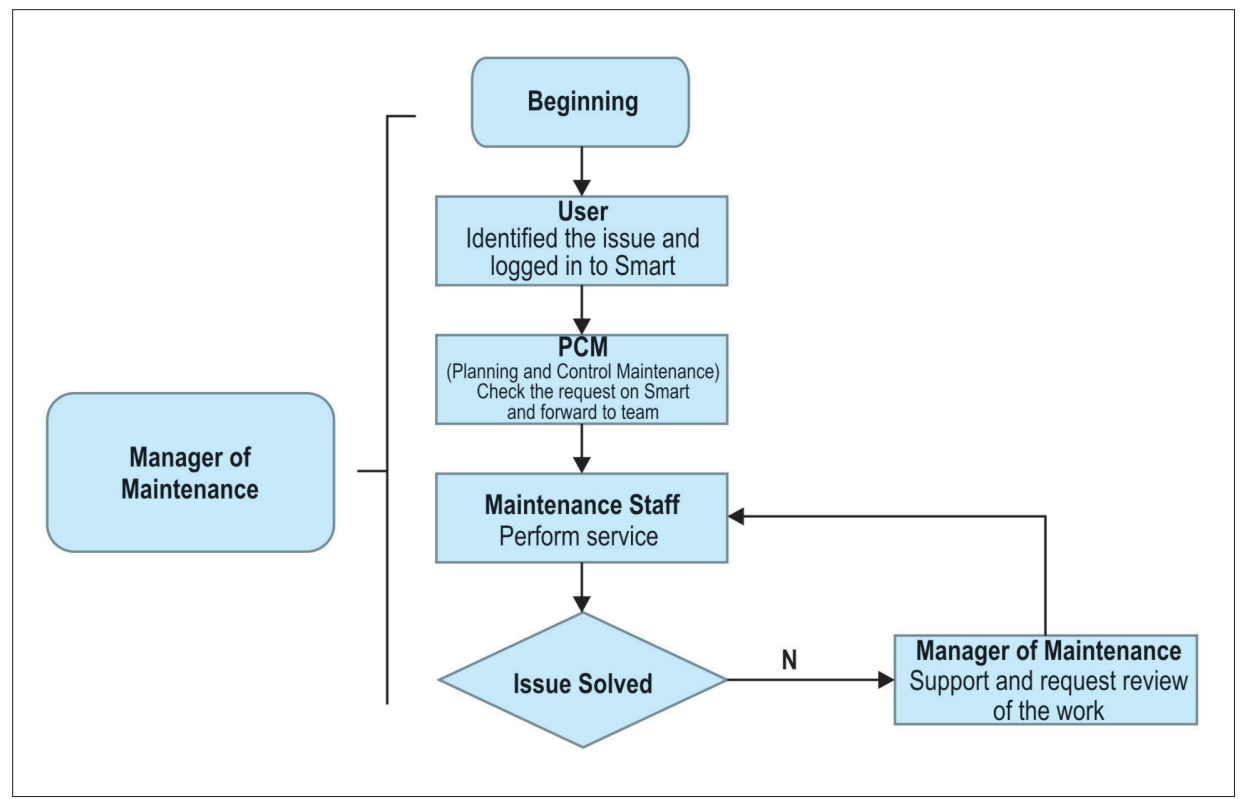

The flowchart in Figure 3 illustrates the steps for the opening, conducting and control of corrective maintenance.

\section{System Deployment}

After the planning steps, the step of collecting data and parameter settings for structuring the operational database system was initiated. Figure
4 shows the initial screen for the data to access the system.

The infrastructure equipment to be inserted in the system was initially defined, and equipment groups were created to facilitate the identification of assets and their management of the operation. After entering the equipment, setting the criticality of material was also carried out to classify the 
Figure 4. Smart system access screen.

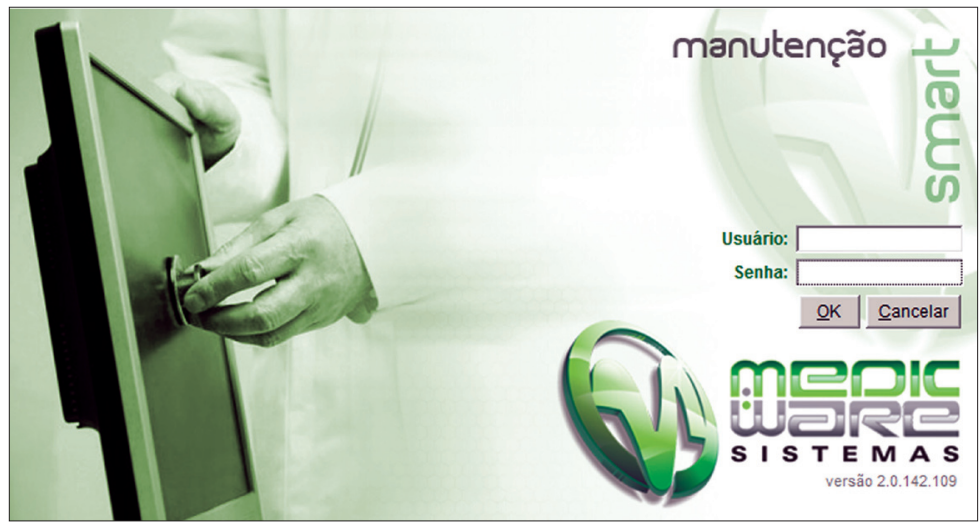

Source:MedicWare (2018).

requests and orders of service according to the degree of importance of the asset before the drive.

The criticality of assets as defined in 4 categories, below:

a) Low-active, which does not interfere with the operation of the unit nor the safety of users.

b) Medium-active, which can interfere with the operation of the unit, but does not interfere with the protection of users.

c) High-active, which interferes directly in the process of the unit, affecting the productive chair, but does not present risks to users.

d) Urgent-active, which interferes directly in the production of the unit, and puts users at risk.

After the definition of the groups, the of the imported equipment by equipment for entries in the software such as air conditioning, generators, chillers, no-breaks, etc. Due to the particularities of the system, it was necessary to carry out the registration of physical environments as well as equipment, only in this way was it possible to perform the opening of corrective services requests. For the register of the equipment, the information of the essential features of the asset was considered, such as make, model and serial number. It was used to optimize the time of registration in the field of equipment ensuring deadlines. Figure 5illustrates the equipment registration screen.

For the opening of requests for corrective services, it was necessary to register the types of remedial maintenance services, both for equipment and for infrastructure in general. The definition of corrective service requests allows the measurement of data to help in the decision making based on the data collected. Also in this step, the average times foreseen for the resolution of each service request are indicated. The service request resolution period is also made available to the user during the opening of a service request, allowing them to know instantly when their application will be answered.

During the implementation of the software, the preventive maintenance procedures were also defined, to assist the maintenance team in accomplishing and fulfilling the maintenance plans. The entire maintenance team was involved in meetings and brainstorming tapping the experiences of each team member to collect this data. The procedures were recorded in a spreadsheet and then imported into the system.

\section{System Operation}

After the implementation phase, data collection, training and testing the policy went into full operation and became the primary tool for management and maintenance of the EAS. The services department of both corrective maintenance and preventive maintenance began to be managed through the software.

Through a maintenance request, it is possible to perform the control of work orders in the system, such as date, time, equipment, activities to be 
Figure 5. Equipment register.

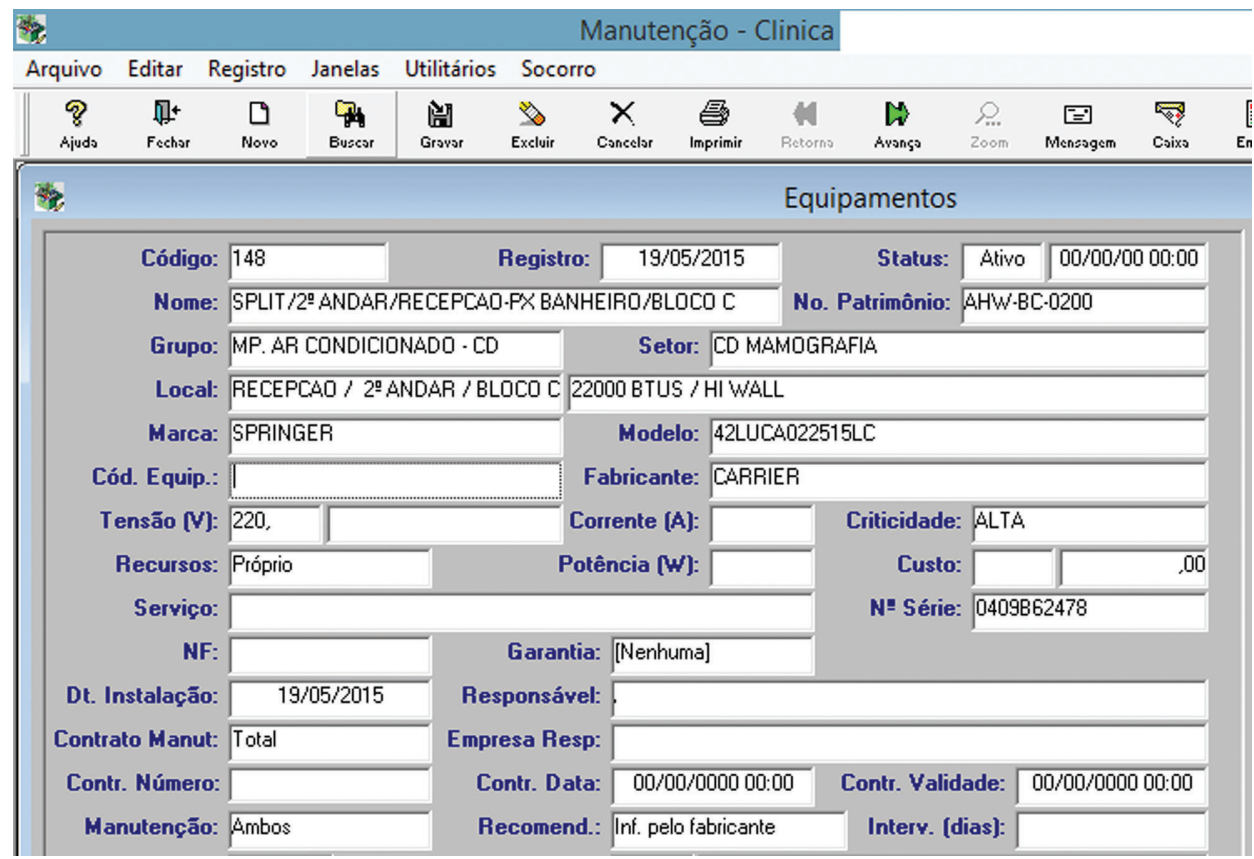

Source:MedicWare (2018).

carried out, the status of orders and services, etc. With the use of the existing filters service orders, groups of equipment, service status, deadlines and a range of information can also be found.

The maintenance teams are requested to perform an activity through a printed document called the service order. With this, the maintenance team can identify the information needed to achieve the operation, such as the applicant, the action that needs to be performed, the location of the equipment and the service sector.

After servicing by a specialized technician, the service is terminated in the system with the upload of the physical document signed by the applicant and the release of all the data recorded by the performer of the service.

\section{Results and Discussion}

With the organization, implementation, and operation of this piece of maintenance software, the process of evaluating and managing the data in the system was initiated. With reliable information about easy access, it was possible to carry out the analysis of the data contributing significantly to decision making and the strategic management of maintenance activities.

Among these actions are the acquisition of new equipment, replacement of equipment, needs for works and repairs, logistics of team attendance among others.

The possibility of measuring data with the elaboration of maintenance indicators is essential to accompany the overall performance of the department. Data are stratified at various levels such as units, locations, sectors, and services, facilitating analysis and problem-solving. After a 12-month cycle of maintenance software operation, the primary data of the department were evaluated to analyze the effectiveness of the implementation of the project. The data for the service orders can be seen in Graphic 1.

The amount of preventive maintenance increased, and corrective maintenance fell by almost 50\%. A survey was also carried out regarding the costs related to the maintenance department. Graphic 2 illustrates these results.

A significant reduction in department costs can be observed, $46.7 \%$ at the end of the year. These data demonstrate the effectiveness of the 
Graphic 1. Preventive service orders x corrective.

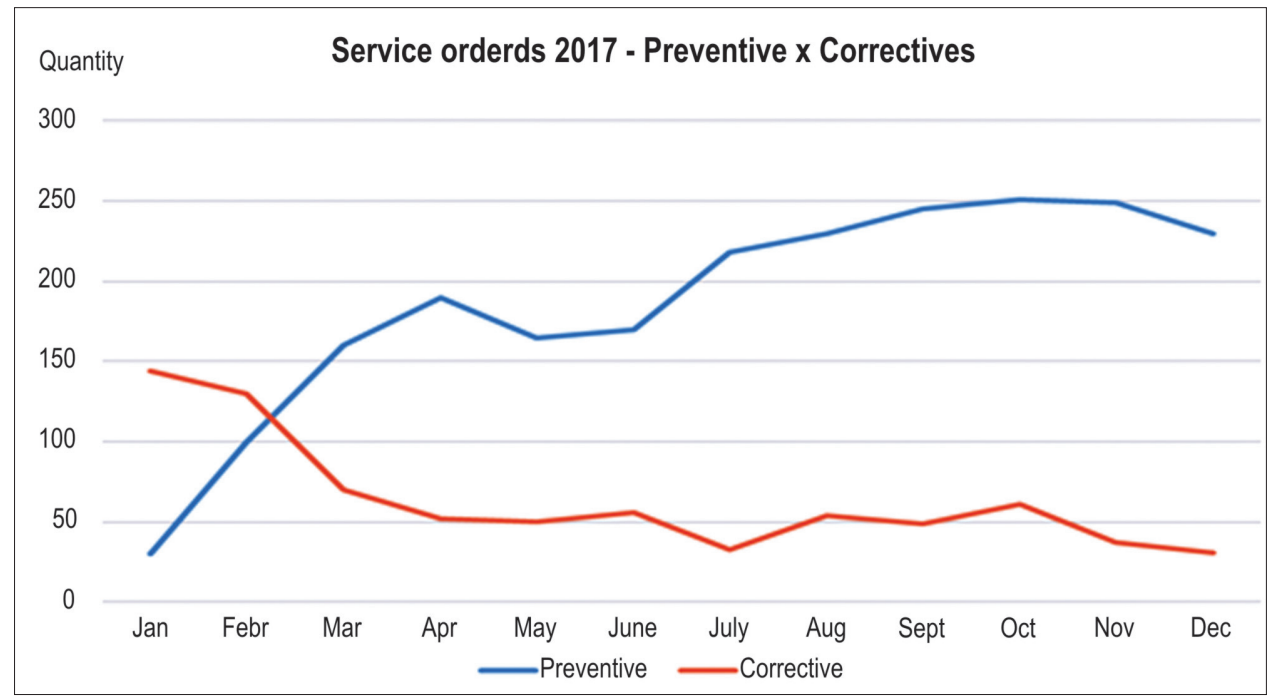

Graphic 2. Cost chart for infrastructure maintenance.

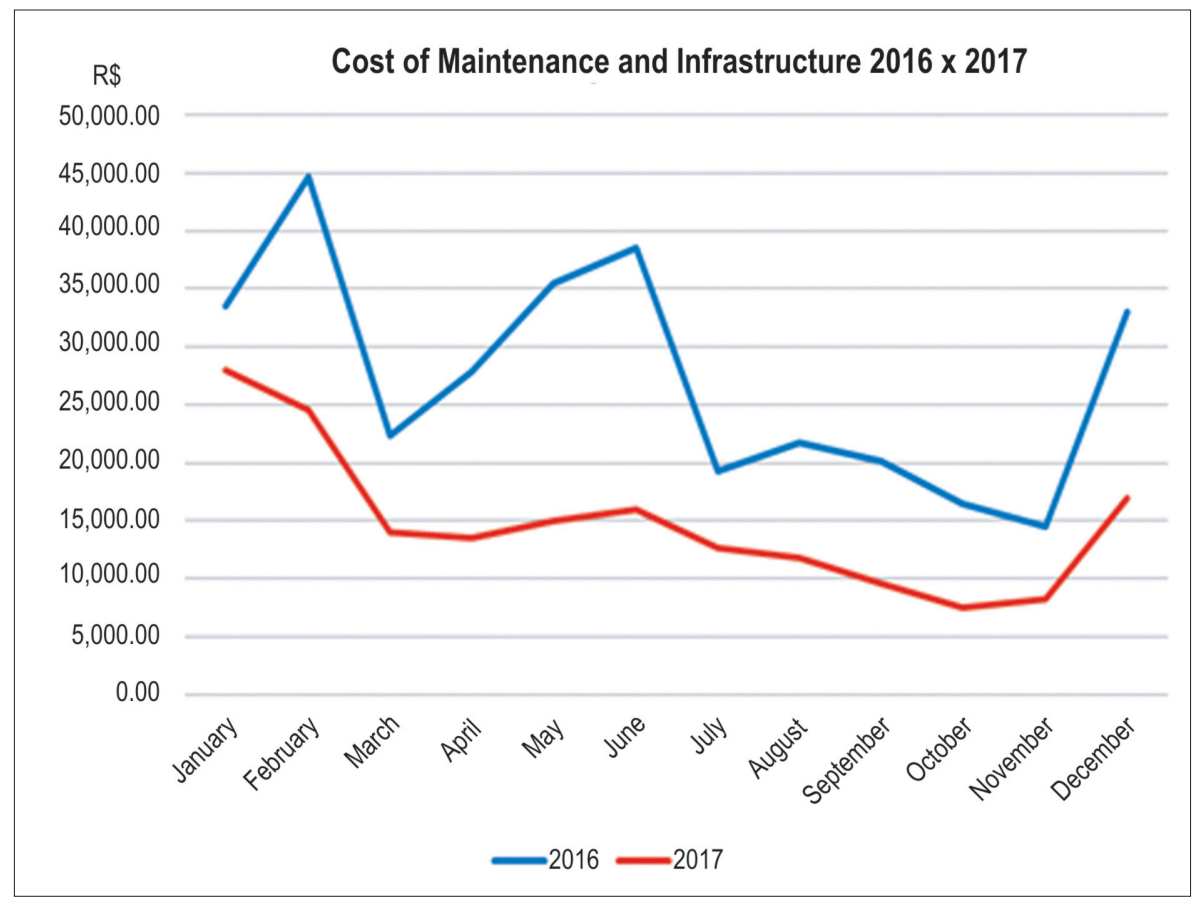

implementation of a maintenance management system and the applicability of maintenance tools in the health care establishment.

\section{Final Considerations}

With the result of the project and the consolidation of the use of the software, it was possible to promote the management of maintenance in the health care establishment. The planning, standardization, and control of the operational routines of the department were consolidated. In this project there was a more significant concern in structuring the maintenance sector initially, adopting simple and satisfactory practices and methods. With the implementation of preventive and corrective maintenance routines, there was an increase in the availability of facilities and equipment, contributing directly and actively to the quality of services provided by the establishment. 
After the presentation of the results to the organization's senior management, the maintenance department became a strategic function in the company, joining this new stage to the Department of Clinical Engineering.

The challenge and the next steps will be to improve the use of the software by implementing new strategies and consolidating practices seeking continuous improvement of processes, and the technical capacity of the team involved to ensure the best results for the Maintenance Management and consequently, for the organization and its users.

\section{References}

1. Gonçalves, E.L. Gestão Hospitalar: administrando o hospital moderno.1. Ed. São Paulo:Saraiva, 2007.

2. Slack, N., Chambers, S., Johnston, R. Administração da Produção. São Paulo: Atlas, 2002.

3. Xenos, H.G. Gerenciando a Manutenção Produtiva. Belo Horizonte: INDG, 2004.

4. Guimarães, J.M.C., Gondim, G.M. O papel da politécnica na formação profissional de técnicos de nível médio envolvidos na área de manutenção predial e de equipamentos em estabelecimentos assistenciais de saúde (EAS), Rio de Janeiro, 2008.

5. Filho, G.B. Auditoria em Manutenção: VIII Congresso de manutenção Semapi. 5. 2003. São Paulo: SEMAPI, 2003.

6. Medic Ware (2018) 


\section{Mosquito Zero ${ }^{\mathrm{TM}}$}

Mosquito Zero is an application that is designed to demonstrate the efficiency and effectiveness of information, education and communication between public authorities and citizens regarding Aedes aegypti, the diseases this mosquito transmits and the health impacts, providing citizens with a smooth and accessible channel of communication about the mosquito and arboviruses through the application and virtual robots.

Using automated point-of-conversation technology (Chatbot for interactivity with the citizen and the city of Salvador, through Facebook, messenger and social network), this is a bot/application that can interact with users of Facebook, Instagram, Tweeter, other applications, and web environments, in an intelligent and humanized way. It responds to and guides users regarding the main problems and related solutions to Aedes aegypti and its pathologies, as well as the information to the public management.

It is an application that has agility and precision, it is fast, friendly and accessible in a technological environment of +1 billion users, with personalized and integrated information of content between public authorities and the user. Mosquito Zero can cross communications and notify the number of users who accessed the bot application; as well as number of user interactions; \% of most accessed organizations; \% of errors and quizzes (evaluation of user knowledge); number of messages that the

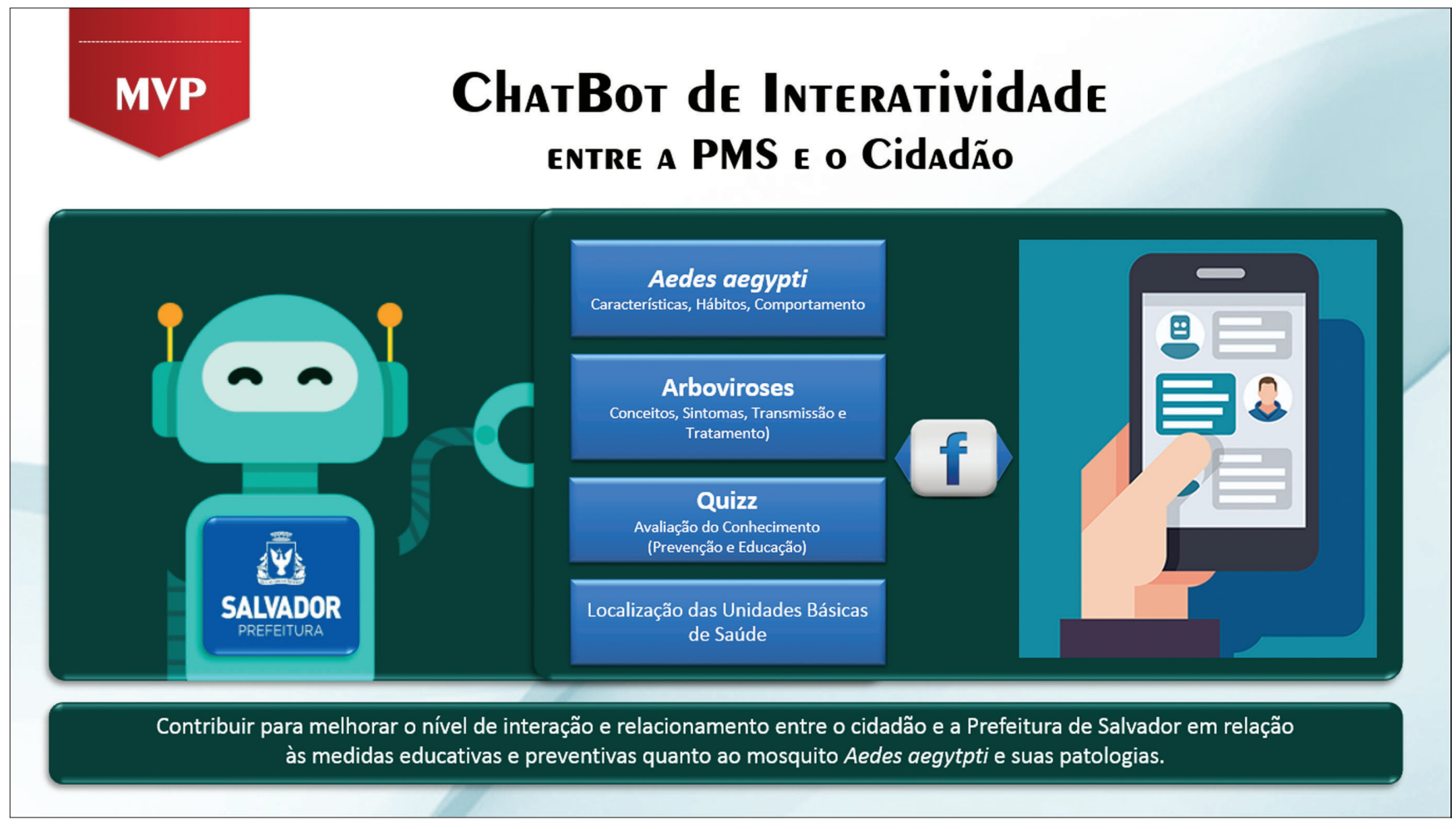

Received on 24 February 2019; revised 6 March 2019.

Address for correspondence: Dr. Alex Sandro Correia.

Zenix Technology. CEO Startup Mosquito Zero. Salvador, Bahia, Brazil. E-mail: alex_spc@hotmail.com.

J Bioeng. Biotech. Appl. Health

2019;2(1):34-35. C 2019 by SENAI CIMATEC. All rights reserved. 
bot was unable to interpret; number of users who re-interacted with the bot; number of users who demonstrated satisfaction with the interaction with the bot.

The application has the following functions:

A - Interaction on Aedes (Morphology, Biology and Behavior);

B - Quiz (Knowledge Assessment) at the primary, intermediate and advanced levels;

C - Geolocation of the nearest health units;

D- Geolocation of vaccination units against yellow fever;

E - Interaction on arbovirus (symptoms, treatment, diagnosis)

F - Preventive measures;

G- Self-service terminal (Bot) for face-to-face evaluation and feedback.

The application is currently installed in a totem in the main shopping malls in the city of Salvador, Bahia, Brazil. The proof of concept is now being validated, evaluating the number of interactions between the user and the robot; interacting with children, young and old, low to medium income population. Furthermore, there is an application which is being validated more specifically by young people who interact with the web, mainly in social networks. It is worth emphasizing that the number of interactions between the user and the robot demonstrates the population's interest in learning about mosquito prevention and control measures in homes.

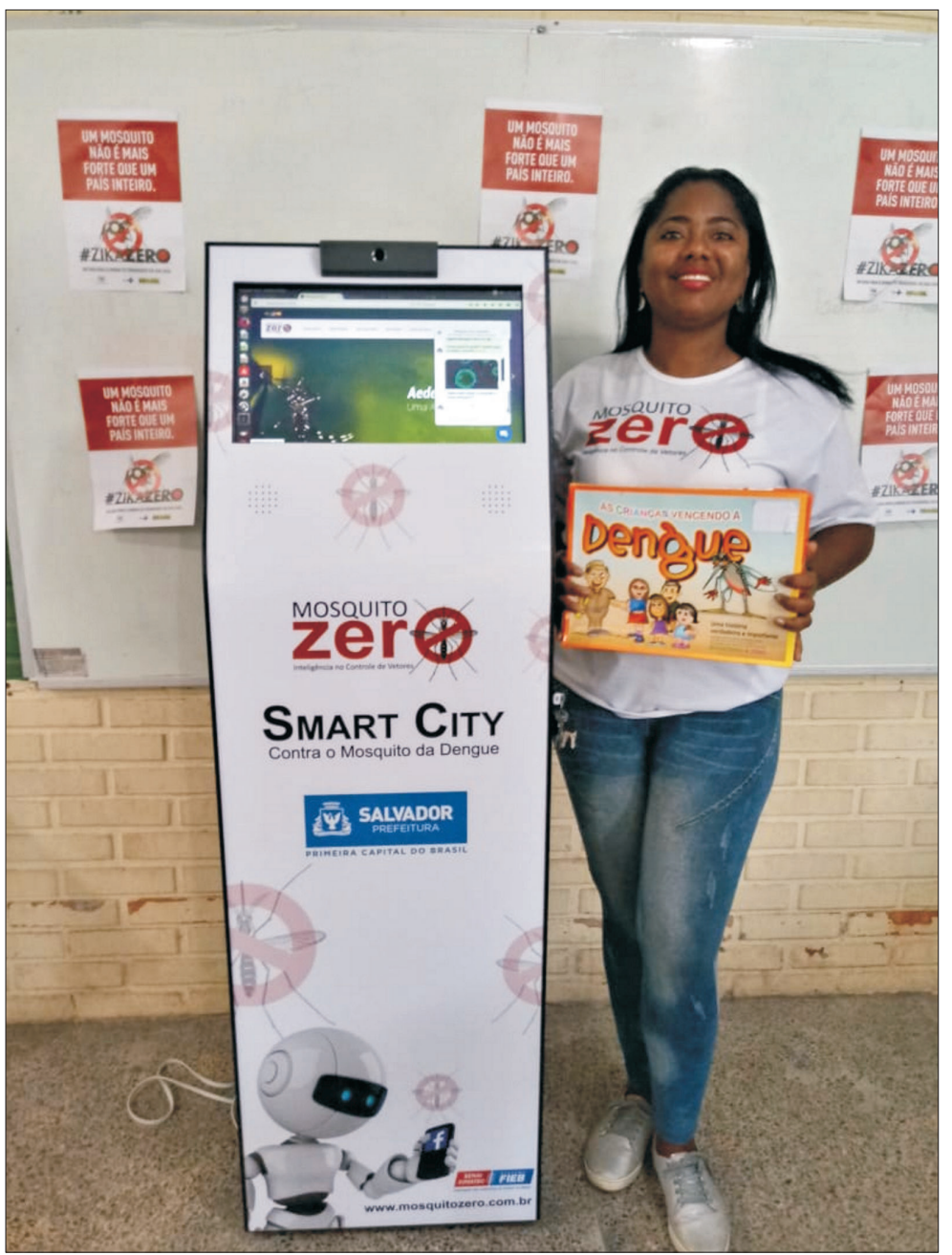




\section{Instructions for Authors}

The Authors must indicate in a cover letter the address, telephone number and e-mail of the corresponding author. The corresponding author will be asked to make a statement confirming that the content of the manuscript represents the views of the co-authors, that neither the corresponding author nor the co-authors have submitted duplicate or overlapping manuscripts elsewhere, and that the items indicated as personal communications in the text are supported by the referenced person. Also, the protocol letter with the number should be included in the submission article, as well as the name of sponsors (if applicable).

Manuscripts may be submitted within designated categories of communication, including:

- Original basic or clinical investigation (original articles on topics of broad interest in the field of bioengineering and biotechnology applied to health). We particularly welcome papers that discuss epidemiological aspects of international health, clinical reports, clinical trials and reports of laboratory investigations.

- Case presentation and discussion (case reports must be carefully documented and must be of importance because they illustrate or describe unusual features or have important practice implications).

- Brief reports of new methods or observations (short communications brief reports of unusual or preliminary findings).
- State-of-the-art presentations (reviews on protocols of importance to readers in diverse geographic areas. These should be comprehensive and fully referenced).

- Review articles (reviews on topics of importance with a new approach in the discussion). However, review articles only will be accepted after an invitation of the Editors.

- Letters to the editor or editorials concerning previous publications (correspondence relating to papers recently published in the Journal, or containing brief reports of unusual or preliminary findings).

- Editor's corner, containing ideas, hypotheses and comments (papers that advance a hypothesis or represent an opinion relating to a topic of current interest).

- Innovative medical products (description of new biotechnology and innovative products applied to health).

- Health innovation initiatives articles (innovative articles of technological production in Brazil and worldwide, national policies and directives related to technology applied to health in our country and abroad).

The authors should checklist comparing the text with the template of the Journal.

Supplements to the JBTH include articles under a unifying theme, such as those summarizing presentations of symposia or focusing on a specific subject. These will be added to the regular publication of the Journal as appropriate, and will be peer reviewed in the same manner as submitted manuscripts.

\section{Statement of Editorial Policy}

The editors of the Journal reserve the right to edit manuscripts for clarity, grammar and style. Authors will have an opportunity to review these changes prior to creation of galley proofs. Changes in content after galley proofs will be sent for reviewing and could be required charges to the author. The JBTH does not accept articles which duplicate or overlap publications elsewhere.

\section{Peer-Review Process}

All manuscripts are assigned to an Associate Editor by the Editor-in-Chief and Deputy
Editor, and sent to outside experts for peer review. The Associate Editor, aided by the reviewers' comments, makes a recommendation to the Editor-in-Chief regarding the merits of the manuscript. The Editor-in-Chief makes a final decision to accept, reject, or request revision of the manuscript. A request for revision does not guarantee ultimate acceptance of the revised manuscript.

Manuscripts may also be sent out for statistical review ou ad hoc reviewers. The average time from submission to first decision is three weeks. 


\section{$\underline{\text { Revisions }}$}

Manuscripts that are sent back to authors for revision must be returned to the editorial office by 15 days after the date of the revision request. Unless the decision letter specifically indicates otherwise, it is important not to increase the text length of the manuscript in responding to the comments. The cover letter must include a point-by-point response to the reviewers and Editors comments, and should indicate any additional changes made. Any alteration in authorship, including a change in order of authors, must be agreed upon by all authors, and a statement signed by all authors must be submitted to the editorial office.

\section{Style}

Manuscripts may be submitted only in electronic form by www.jbthonline.com. Each manuscript will be assigned a registration number, and the author notified that the manuscript is complete and appropriate to begin the review process. The submission file is in OpenOffice, Microsoft Word, or RTF document file format for texts and JPG (300dpi) for figures.

Authors must indicate in a cover letter the address, telephone number, fax number, and e-mail of the corresponding author. The corresponding author will be asked to make a statement confirming that the content of the manuscript represents the views of the co-authors, that neither the corresponding author nor the co-authors have submitted duplicate or overlapping manuscripts elsewhere, and that the items indicated as personal communications in the text are supported by the referenced person.

Manuscripts are to be typed as indicated in Guide for Authors, as well as text, tables, references, legends. All pages are to be numbered with the order of presentation as follows: title page, abstract, text, acknowledgements, references, tables, figure legends and figures. A running title of not more than 40 characters should be at the top of each page. References should be listed consecutively in the text and recorded as follows in the reference list, and must follow the format of the National Library of Medicine as in Index Medicus and "'Uniform Requirements for Manuscripts Submitted to Biomedical Journals" or in "Vancouver Citation Style". Titles of journals not listed in Index Medicus should be spelled out in full.

Manuscript style will follow accepted standards. Please refer to the JBTH for guidance. The final style will be determined by the Editor-in-Chief as reviewed and accepted by the manuscript's corresponding author.

\section{Approval of the Ethics Committee}

The JBTH will only accept articles that are approved by the ethics committees of the respective institutions (protocol number and/or approval certification should be sent after the references). The protocol number should be included in the end of the Introduction section of the article.

\section{Publication Ethics}

Authors should observe high standards with respect to publication ethics as set out by the International Committee of Medical Journal Editors (ICMJE). Falsification or fabrication of data, plagiarism, including duplicate publication of the authors' own work without proper citation, and misappropriation of the work are all unacceptable practices. Any cases of ethical misconduct are treated very seriously and will be dealt with in accordance with the JBTH guidelines.

\section{Conflicts of Interest}

At the point of submission, each author should reveal any financial interests or connections, direct or indirect, or other situations that might raise the question of bias in the work reported or the conclusions, implications, or opinions stated - including pertinent commercial or other sources of funding for the individual author(s) or for the associated department(s) or organizations(s), and personal relationships. There is a potential conflict of interest when anyone involved in the publication process has a financial or other beneficial interest in 
the products or concepts mentioned in a submitted manuscript or in competing products that might bias his or her judgment.

\section{Material Disclaimer}

The opinions expressed in JBTH are those of the authors and contributors, and do not necessarily reflect those of the ITS/SENAI CIMATEC, the editors, the editorial board, or the organization with which the authors are affiliated.

\section{Privacy Statement}

The names and email addresses entered in this Journal site will be used exclusively for the stated purposes of this journal and will not be made available for any other purpose or to any other party.

\section{Brief Policies of Style}

\begin{tabular}{|c|c|c|c|c|c|c|c|c|}
\hline Manuscript & Original & Review & $\begin{array}{c}\text { Birief } \\
\text { Comunication }\end{array}$ & Case Report & $\begin{array}{l}\text { Editorial ; Letter } \\
\text { to the Editor; } \\
\text { Editor's Corner }\end{array}$ & $\begin{array}{c}\text { Innovative } \\
\text { Medical } \\
\text { Products }\end{array}$ & State-of-the-Art & $\begin{array}{c}\text { Health } \\
\text { Innovation } \\
\text { Initiatives }\end{array}$ \\
\hline Font Type & Times or Arial & Times or Arial & Times or Arial & Times or Arial & Times or Arial & Times or Arial & Times or Arial & Times or Arial \\
\hline $\begin{array}{l}\text { Number of Words } \\
\text { - Title }\end{array}$ & 120 & 90 & 95 & 85 & 70 & 60 & 120 & 90 \\
\hline $\begin{array}{l}\text { Font Size/Space- } \\
\text { Title }\end{array}$ & 12; double space & 12; double space & 12; double space & 12; double space & 12; double space & 12; double space & 12; double space & 12; double space \\
\hline $\begin{array}{l}\text { Font Size/Space- } \\
\text { Abstracts/Key } \\
\text { Words and } \\
\text { Abbreviations }\end{array}$ & 10; single space & 10; single space & 10; single space & 10; single space & - & - & 10; single space & 10; single space \\
\hline $\begin{array}{l}\text { Number of Words } \\
\text {-Abstracts/Key } \\
\text { Words }\end{array}$ & $300 / 5$ & $300 / 5$ & $200 / 5$ & $250 / 5$ & - & - & $300 / 5$ & $300 / 5$ \\
\hline $\begin{array}{l}\text { Font Size/Space- } \\
\text { Text }\end{array}$ & 12; Double space & 12; Double space & 12; Double space & 12; Double space & 12; Double space & 12; Double space & 12; Double space & 12; Double space \\
\hline $\begin{array}{l}\text { Number of Words } \\
- \text { Text }\end{array}$ & $\begin{array}{l}5,000 \text { including } \\
\text { spaces }\end{array}$ & $\begin{array}{l}5,500 \text { including } \\
\text { spaces }\end{array}$ & $\begin{array}{l}2,500 \text { including } \\
\text { spaces }\end{array}$ & $\begin{array}{l}1,000 \text { including } \\
\text { spaces }\end{array}$ & $\begin{array}{l}1,000 \text { including } \\
\text { spaces }\end{array}$ & $\begin{array}{l}550 \text { including } \\
\text { spaces }\end{array}$ & $\begin{array}{l}5,000 \text { including } \\
\text { spaces }\end{array}$ & $\begin{array}{l}5,500 \text { including } \\
\text { spaces }\end{array}$ \\
\hline $\begin{array}{l}\text { Number of } \\
\text { Figures }\end{array}$ & $\begin{array}{c}8 \text { (title font size } \\
12 \text {, double space) }\end{array}$ & $\begin{array}{c}3 \text { (title font size } \\
12 \text {, double space) }\end{array}$ & $\begin{array}{c}2 \text { (title font size } \\
12 \text {, double space) }\end{array}$ & $\begin{array}{c}2 \text { (title font size } \\
12 \text {, double space) }\end{array}$ & - & $\begin{array}{c}2 \text { (title font size } \\
12 \text {, double space) }\end{array}$ & $\begin{array}{c}8 \text { (title font size } \\
12 \text {, double space) }\end{array}$ & $\begin{array}{c}8 \text { (title font size } \\
12, \text { double space) }\end{array}$ \\
\hline $\begin{array}{l}\text { Number of } \\
\text { Tables/Graphic }\end{array}$ & $\begin{array}{c}7 \text { title font size } 12 \\
\text { double space }\end{array}$ & $\begin{array}{c}2 \text { title font size } 12 \\
\text { double space }\end{array}$ & $\begin{array}{c}\text { 2(title font size } 12 \\
\text { double space) }\end{array}$ & $\begin{array}{c}\text { 1(title font size } 12 \\
\text { double space) }\end{array}$ & - & - & $\begin{array}{l}7 \text { title font size } 12 \\
\text { double space }\end{array}$ & $\begin{array}{c}4 \text { title font size } 12 \\
\text { double space }\end{array}$ \\
\hline $\begin{array}{l}\text { Number of } \\
\text { Authors and Co- } \\
\text { authors }{ }^{*}\end{array}$ & 15 & 10 & 5 & 10 & 3 & 3 & 15 & 10 \\
\hline References & $\begin{array}{c}20 \text { (font size } \\
10, \text { single space }\end{array}$ & $\begin{array}{c}30 \text { (font size } \\
10, \text { single space }\end{array}$ & $\begin{array}{c}15 \text { (font size } \\
10, \text { single space) }\end{array}$ & $\begin{array}{c}10 \text { (font size } \\
10, \text { single space) }\end{array}$ & $\begin{array}{c}10 \text { (font size } \\
10, \text { single space }\end{array}$ & $\begin{array}{c}5 \text { (font size } \\
10, \text { single space }\end{array}$ & $\begin{array}{c}20 \text { (font size } \\
10 \text {,single space }\end{array}$ & 20 \\
\hline
\end{tabular}

*First and last name with a sequencing overwritten number. Corresponding author(s) should be identified with an asterisk; Type 10, Times or Arial, single space. Running title of not more than 40 characters should be at the top of each page. References should be listed consecutively in the text. References must be cited on (not above) the line of text and in brackets instead of parentheses, e.g., [7,8]. References must be numbered in the order in which they appear in the text. References not cited in the text cannot appear in the reference section. References only or first cited in a table or figures are numbered according to where the table or figure is cited in the text. For instance, if a table is placed after reference 8 , a new reference cited in table 1 would be reference 9 . 


\section{Checklist for Submitted Manuscripts}

$\square$ 1. Please provide a cover letter with your submission specifying the corresponding author as well as an address, telephone number and e-mail.

2. Submit your paper using our website www.jbthonline.com. Use Word Perfect/Word for Windows, each with a complete set of original illustrations.

口3. The entire manuscript (including tables and references) must be typed according to the guidelines instructions.

4. The order of appearance of material in all manuscripts should be as follows: title page, abstract, text, acknowledgements, references, tables, figures/graphics/diagrams with the respective legends.

口5. The title page must include a title of not more than three printed lines (please check the guidelines of each specific manuscript), authors (no titles or degrees), institutional affiliations, a running headline of not more than 40 letters with spaces.

口6. Acknowledgements of persons who assisted the authors should be included on the page preceding the references.

$\square 7$. References must begin on a separate page.

$\square$ 8. References must be cited on (not above) the line of text and in brackets instead of parentheses, e.g., $[7,8]$.

口9. References must be numbered in the order in which they appear in the text. References not cited in the text cannot appear in the reference section. References only or first cited in a table or figures are numbered according to where the table or figure is cited in the text. For instance, if a table is placed after reference 8 , a new reference cited in table 1 would be reference 9.

10. Reference citations must follow the format established by the "Uniform Requirements for Manuscripts Submitted to Biomedical Journals" or in "Vancouver Citation Style".

11. If you reference your own unpublished work (i.e., an "in press" article) in the manuscript that you are submitting, you must attach a file of the "in press" article and an acceptance letter from the journal.

12. If you cite unpublished data that are not your own, you must provide a letter of permission from the author of that publication.

13. Please provide each figure in high quality (minimum 300 dpi: JPG or TIF). Figure must be on a separate file.

14. If the study received a financial support, the name of the sponsors must be included in the cover letter and in the text, after the author's affiliations.

15. Provide the number of the Ethics Committees (please check the guidelines for authors). 


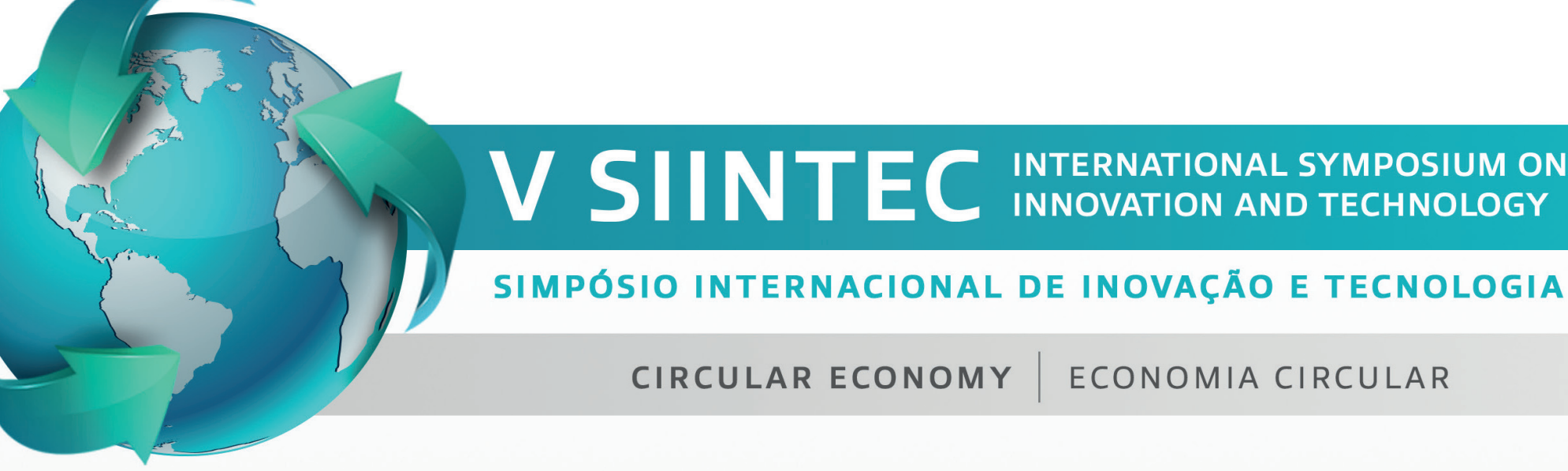

The International Symposium on Innovation and Technology (SIINTEC) happens since 2015. The annual event is promoted by SENAI CIMATEC. The objective of the event is to contribute significantly to the scientific and technological development in Brazil, seeking the massive participation between academy and industry involved in research, development and innovation.

The V SIINTEC will be held from October 09-11, 2019, and has the theme: "Circular Economy". The event will give opportunity to discuss the main topics related to technological innovations as basis for meeting the challenges of productive processes.

The event has an annual publication of complete works with registration by the Brazilian Institute of Information in Science and Technology (IBICTI). Through this yearbook of published papers, it is possible to measure the impact and interest of the scientific community in the dissemination of the researches that has been developed in Brazil and around the World. Three yearbooks will have specific sessions for publication: Modeling and Industrial Technology, Management and Industrial Technology, Engineering, SENAI Institute of Innovation and Sustainable Development.

DATE OF EVENT

PAPER SUBMISSION DEADLINE

FINAL PAPER SUBMISSION DEADLINE
October 09-11, 2019

August 15, 2019

September 13, 2019

September 30, 2019

RESULT OF THE APPROVED PAPERS
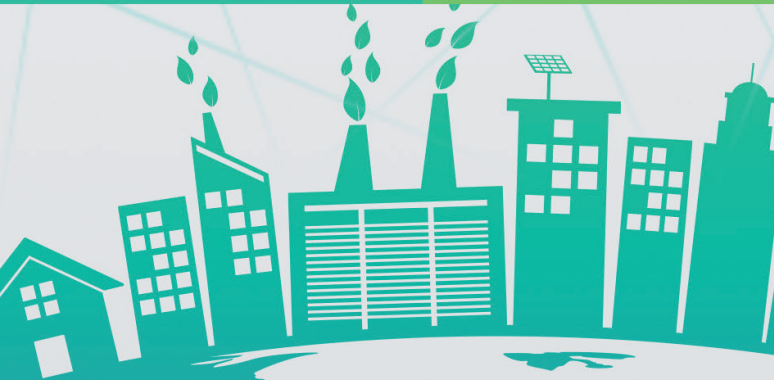
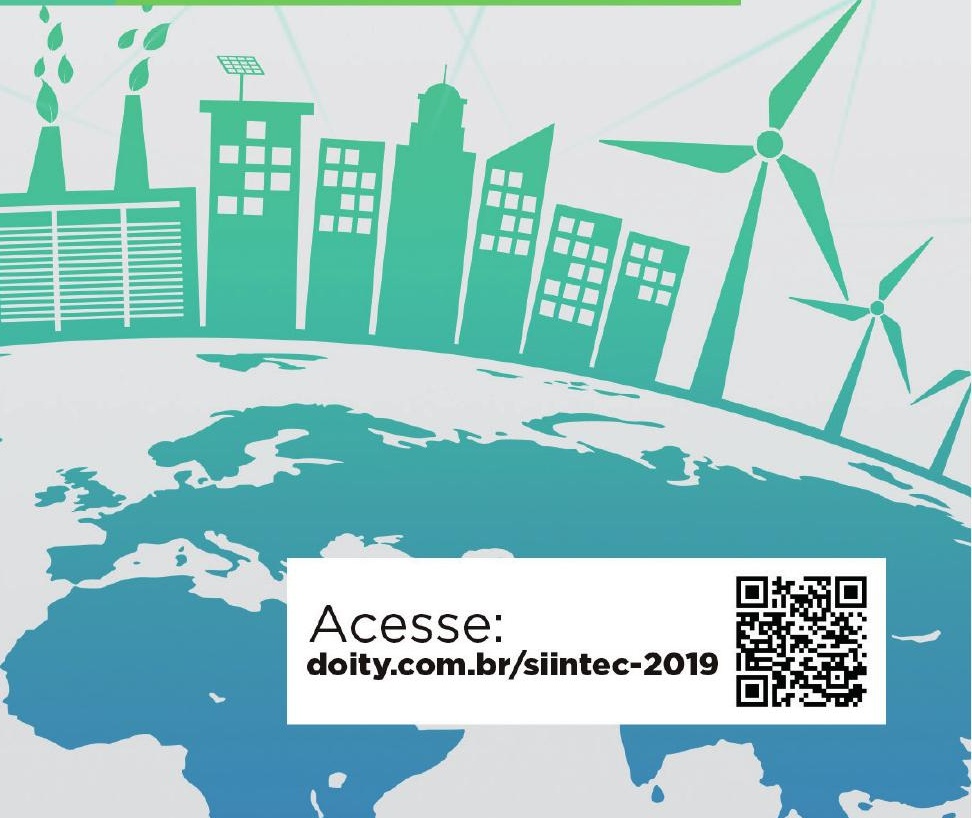

\section{Acesse:} doity.com.br/siintec-2019 